\title{
A land surface model combined with a crop growth model for paddy rice (MATCRO-Rice v. 1) - Part 1: Model description
}

\author{
Yuji Masutomi $^{1}$, Keisuke Ono ${ }^{2}$, Masayoshi Mano ${ }^{3}$, Atsushi Maruyama ${ }^{2}$, and Akira Miyata ${ }^{2}$ \\ ${ }^{1}$ College of Agriculture, Ibaraki University, 3-21-1, Chuo, Ami, Inashiki, Ibaraki 300-0393, Japan \\ ${ }^{2}$ Institute for Agro-Environmental Sciences, NARO, 3-1-3, Kannondai, Tsukuba, Ibaraki 305-8604, Japan \\ ${ }^{3}$ Graduate School of Horticulture, Chiba University, 648 Matsudo, Matsudo-shi, Chiba 271-8510, Japan \\ Correspondence to: Yuji Masutomi (yuji.masutomi@gmail.com)
}

Received: 5 February 2016 - Published in Geosci. Model Dev. Discuss.: 24 February 2016

Revised: 15 July 2016 - Accepted: 22 July 2016 - Published: 21 November 2016

\begin{abstract}
Crop growth and agricultural management can affect climate at various spatial and temporal scales through the exchange of heat, water, and gases between land and atmosphere. Therefore, simulation of fluxes for heat, water, and gases from agricultural land is important for climate simulations. A land surface model (LSM) combined with a crop growth model (CGM), called an LSM-CGM combined model, is a useful tool for simulating these fluxes from agricultural land. Therefore, we developed a new LSM-CGM combined model for paddy rice fields, the MATCRO-Rice model. The main objective of this paper is to present the full description of MATCRO-Rice. The most important feature of MATCRO-Rice is that it can consistently simulate latent and sensible heat fluxes, net carbon uptake by crop, and crop yield by exchanging variables between the LSM and CGM. This feature enables us to apply the model to a wide range of integrated issues.
\end{abstract}

\section{Introduction}

In the last 15 years, climate and land surface modelling studies have shown that crop growth and farm management in agricultural land significantly affect climate via the exchange of heat, water, and gases. For example, applying a regional climate model combined with a crop growth model (CGM) to the United States, Tsvetsinskaya et al. (2001) showed that crop growth can change the surface temperature by $2-4{ }^{\circ} \mathrm{C}$. Maruyama and Kuwagata (2010) showed that crop growing season can affect the amount of evapotranspiration by using a land surface model (LSM) combined with a CGM. Levis et al. (2012) incorporated a CGM into an earth system model, and showed that the timing of crop sowing can change the amount of precipitation. Using a dynamic global vegetation model combined with a CGM, Bondeau et al. (2007) showed that the global carbon cycle, which has a significant effect on global warming, is largely modified by crop growth and farm management. Osborne et al. (2009), using a global climate model coupled with a CGM, demonstrated that the cropclimate interaction can affect annual variability in surface temperature. All these studies indicate that crop growth and farm management are key determinants of climate and that climate simulations need to simulate the fluxes of heat, water, and gases in agricultural land.

An LSM or dynamic vegetation model (DVM) incorporated with a CGM, called LSM-CGM or DVM-CGM combined models, are a useful tool for simulating the fluxes of heat, water, and gases in agricultural land. Hence, several LSMs and DVMs incorporated with a CGM have been developed (BATS-GF: Tsvetsinskaya et al., 2001; AgroIBIS: Kucharik, 2003; ORCHIDEE-STICS: Gervois et al., 2004; LPJmL: Bondeau et al., 2007; GLAM-MOSES2: Osborne et al., 2007; SIBcrop: Lokupitiya et al., 2009; MK10: Maruyama and Kuwagata, 2010; CLM4CNcrop: Levis et al., 2012; JULES-crop: Osborne et al., 2015). Lei et al. (2010) divided these incorporated models into three types in terms of integration schemes for the leaf area index (LAI). Among these types, the type of models that consistently simulate crop production, LAI, water-energy flux, and carbon uptake by exchanging variables between an LSM and a CGM allows for wide applicability and comprehensive evaluation of the model with observations (Lei et al., 2010). However, 
this type comprises currently only four models: Agro-IBIS, SIBcrop, CLM4CNcrop, and JULES-crop. Among these, only JULES-crop can simulate the growth of rice, although rice is one of the major crops, accounting for $23 \%$ of agricultural land farmed with cereals worldwide (FAO, 2015). Nevertheless, the JULES-crop model does not consider the flooded and irrigated surface of paddy rice fields, which is an important parameter when simulating heat and water fluxes in paddy rice fields, because heat and water fluxes in a flooded and irrigated surface are largely different from those in a non-flooded and rain-fed surface (e.g. Boucher et al., 2004; Lobell et al., 2006; Kueppers et al., 2008).

We developed a new LSM-CGM model, called MATCRORice. The aim of this paper is to describe the MATCRO-Rice model in detail. The most important feature of MATCRORice is that it can consistently simulate latent heat flux (LHF), sensible heat flux (SHF), net carbon uptake by crop, and crop yields by exchanging variables between the LSM and CGM. Herein, we first provide the overview of MATCRO-Rice in Sect. 2, and then describe the LSM and CGM of MATCRO-Rice in detail in Sects. 3 and 4, respectively. Last, we discuss the applications and limitations of MATCRO-Rice in Sect. 5. The model validation for MATCRO-Rice is described in the accompanied paper (Masutomi et al., 2016).

\section{Model overview: MATCRO-Rice}

MATCRO-Rice has two main components: LSM and CGM. The LSM component mainly simulates LHF and SHF. It is based on MATSIRO (Takata et al., 2003), which is embedded in global climate models (MIROC5.0: Watanabe et al., 2010; NICAM: Satoh et al., 2008) and a climate system model (MIROC-ESM: Watanabe et al., 2011). In addition, MATSIRO is used for a range of hydrological applications (e.g. Pokhrel et al., 2012; Hirabayashi et al., 2013).

The CGM of MATCRO-Rice mainly simulates rice yield and biomass for each organ during a growing period. The CGM used in MATCRO-Rice is based on CGMs developed by the school of de Wit (Bouman et al., 1996; e.g. MACROS: Penning de Vries et al., 1989; SUCROS: Goudriaan and van Laar, 1994; ORYZA2000: Bouman et al., 2001).

The meteorological inputs to run MATCRO-Rice are listed in Table 1. The standard outputs of MATCRO-Rice are LHF, SHF, biomass of organs during a growing period, and crop yield. All other variables simulated in MATCRO-Rice can be output if needed. The feature of MATCRO-Rice is to exchange variables between the LSM and CGM. The variables exchanged are listed in Table 2.

In the present paper, we describe MATCRO only for rice. The model structure of MATCRO, however, is valid for other crops. Therefore, MATCRO can be applied to other crops if the model parameters for other crops are given.
Table 1. Meteorological inputs.

\begin{tabular}{|c|c|c|}
\hline Variable & Unit & Description \\
\hline$P_{\mathrm{a}}$ & $\mathrm{Pa}$ & Air pressure \\
\hline$P_{\mathrm{r}}$ & $\mathrm{kg} \mathrm{m}^{-2} \mathrm{~s}^{-1}$ & Precipitation \\
\hline$Q$ & $\mathrm{~kg} \mathrm{~kg}^{-1}$ & Specific humidity \\
\hline$R_{\mathrm{S}}^{\mathrm{d}}(0)$ & $\mathrm{W} \mathrm{m}^{-2}$ & $\begin{array}{l}\text { Downward shortwave radiant flux } \\
\text { density at the canopy top }\end{array}$ \\
\hline$R_{1}^{\mathrm{d}}(0)$ & $\mathrm{W} \mathrm{m}^{-2}$ & $\begin{array}{l}\text { Downward longwave radiant flux } \\
\text { density at the canopy top }\end{array}$ \\
\hline$T_{\mathrm{a}}$ & $\mathrm{K}$ & Air temperature \\
\hline$U$ & $\mathrm{~ms}^{-1}$ & Wind speed \\
\hline
\end{tabular}

\section{Land surface model}

The main outputs of the LSM of MATCRO-Rice are LHF and SHF. The LSM has five modules, which are energy balance at the canopy and surface, within-canopy shortwave radiation, bulk transfer coefficient for latent and sensible heat, canopy water balance, and soil water and heat transfer. Each module is described in detail in the following sections. Before describing each module, we note the following two major modifications from the original LSM, MATSIRO (Takata et al., 2003).

1. LAI, crop height, and root depth, which are constant in the original MATSIRO, are dynamically calculated in the CGM and are the inputs to the LSM.

2. Surface water is added above the soil surface in the case of flooded surface.

Other minor modifications are described separately in each of the following sections. Table 3 shows all the modifications of the original model. We note that the photosynthesis model used in MATCRO is described in the CGM section (Sect. 4).

\subsection{Energy balance at the canopy and surface}

This module calculates LHF and SHF by solving energy balance at two layers, canopy and surface. The module is based on the original MATSIRO (Takata et al., 2003), except for the addition of surface water above the soil in the case of flooded surface and other minor modifications. The energy balance at the canopy and surface are given as follows:

$$
\begin{aligned}
& R_{\mathrm{nc}}=H_{\mathrm{c}}+\lambda E_{\mathrm{c}}+\lambda E_{\mathrm{t}}, \text { (canopy) } \\
& R_{\mathrm{ng}}=H_{\mathrm{g}}+\lambda E_{\mathrm{g}}+G_{\mathrm{gs}}+S_{\mathrm{tw}}, \text { (surface) }
\end{aligned}
$$

where $R_{\mathrm{nc}}$ and $R_{\mathrm{ng}}$ are the net radiant flux density at canopy and surface; $H_{\mathrm{c}}$ and $H_{\mathrm{g}}$ are the SHF from the canopy and surface; $E_{\mathrm{c}}, E_{\mathrm{t}}$, and $E_{\mathrm{g}}$ are the evaporation from wet canopy, transpiration from the canopy, and evaporation from the surface, respectively; $G_{\mathrm{gs}}$ is the heat flux from the surface to soil; and $S_{\mathrm{tw}}$ is the heat flux stored into surface water in the 
Table 2. Variables exchanged between the land surface model (LSM) and crop growth model (CGM).

\begin{tabular}{|c|c|c|}
\hline Variable & Unit & Description \\
\hline \multicolumn{3}{|c|}{ LSM to CGM } \\
\hline$D_{1}^{\mathrm{d}}(l)$ & $\mathrm{W} \mathrm{m} \mathrm{m}^{-2}$ & $\begin{array}{l}\text { direct downward radiant flux density for photosynthesis active radiation } \\
\text { (PAR) at a leaf area index (LAI) depth of } l\end{array}$ \\
\hline$S_{1}^{\mathrm{d}}(l)$ & $\mathrm{W} \mathrm{m}^{-2}$ & scattered downward radiant flux density for PAR at a LAI depth of $l$ \\
\hline$S_{1}^{\mathrm{u}}(l)$ & $\mathrm{W} \mathrm{m}^{-2}$ & scattered upward radiant flux density for PAR at a LAI depth of $l$ \\
\hline$T_{\mathrm{c}}$ & $\mathrm{K}$ & canopy temperature \\
\hline \multicolumn{3}{|c|}{ CGM to LSM } \\
\hline $\bar{g}_{\mathrm{s}}$ & $\mathrm{m} \mathrm{s}^{-1}$ & stomatal conductance per unit leaf area for both sides of the leaf \\
\hline$h_{\mathrm{gt}}$ & & canopy height \\
\hline$L$ & $\mathrm{~m}^{2} \mathrm{~m}^{-2}$ & LAI \\
\hline$W_{\text {sh }}$ & $\mathrm{kg} \mathrm{a}^{-1}$ & dry matter weight of shoot \\
\hline$z_{\mathrm{rt}}$ & $\mathrm{m}$ & root depth \\
\hline
\end{tabular}

Table 3. Modifications from the original model, MATSIRO.

\begin{tabular}{lll}
\hline Eq. & MATCRO & MATSIRO \\
\hline 11 & Flooded surface & Not considered \\
$15-19$ & Goudriaan and van Laar (1994) & Goudriaan (1977) \\
25 & Watanabe (1994) & {$\left[1 / C_{H_{\mathrm{c}}}+U /\left(\bar{g}_{\mathrm{st}} L / 2\right)\right]^{-1}$} \\
31 and 32 & Campbell and Norman (1998) & Unknown \\
36 & Maruyama and Kuwagata (2008) & $\frac{\Theta_{0} C_{M}^{3 / 2} U^{2}}{\mathrm{Kg}_{H_{\mathrm{g}}}\left(T_{\mathrm{g}}-T_{\mathrm{a}}\right)}$ \\
37 & Campbell and Norman (1998) & $300 \mathrm{~K}$ \\
45 & Penning de Vries et al. (1989) & $0.2 L$ \\
50 & Campbell and Norman (1998) and Best et al. (2011) & Default fixed values for each soil type are given \\
54 & Flooded surface & Not considered \\
$55\left(z_{\mathrm{b}}<z \leq z_{\max }\right)$ & Hanasaki et al. (2008) & Beven and Kirkby (1979) \\
59 & Calculated from the assumption that root has no & Default fixed values for each vegetation type \\
& spatial orientation & are given \\
$63-109$ & de Pury and Farquhar (1997) and Dai et al. (2004) & Sellers et al. (1992, 1996a) \\
$110-141$ & Crop development and growth & Not considered \\
\hline
\end{tabular}

case of flooded surface. It is important to note that the downward flux for $R_{\mathrm{nc}}, R_{\mathrm{ng}}$, and $G_{\mathrm{gs}}$ indicates a positive flux, whereas downward flux for $H_{\mathrm{c}}, H_{\mathrm{g}}, E_{\mathrm{c}}, E_{\mathrm{t}}$, and $E_{\mathrm{g}}$ indicates a negative flux. All variables in the model are listed in Table 4 . $\lambda$ is the physical constant for the latent heat of vaporization (Table 5). Each of the radiant, heat, and water fluxes in Eqs. (1) and (2) are given by the following equations.

$$
\begin{aligned}
& R_{\mathrm{nc}}=\left(R_{\mathrm{s}}^{\mathrm{d}}(0)-R_{\mathrm{s}}^{\mathrm{u}}(0)\right)\left(1-\tau_{\mathrm{cs}}\right)+\epsilon R_{1}^{\mathrm{d}}(0)\left(1-\tau_{\mathrm{cl}}\right) \\
& \quad-\left(2 \epsilon \sigma T_{\mathrm{c}}^{4}-\epsilon \sigma T_{\mathrm{g}}^{4}\right)\left(1-\tau_{\mathrm{cl}}\right) \\
& R_{\mathrm{ng}}=\left(R_{\mathrm{s}}^{\mathrm{d}}(0)-R_{\mathrm{s}}^{\mathrm{u}}(0)\right) \tau_{\mathrm{cs}}+\epsilon R_{1}^{\mathrm{d}}(0) \tau_{\mathrm{cl}}-\epsilon \sigma T_{\mathrm{g}}^{4} \\
& \quad+\epsilon \sigma\left(1-\tau_{\mathrm{cl}}\right) T_{\mathrm{c}}^{4} \\
& H_{\mathrm{c}}=c_{\mathrm{pa}} \rho_{\mathrm{a}} C_{H_{\mathrm{c}}} U\left(T_{\mathrm{c}}-T_{\mathrm{a}}\right),
\end{aligned}
$$

$$
\begin{aligned}
& H_{\mathrm{g}}=c_{\mathrm{pa}} \rho_{\mathrm{a}} C_{H_{\mathrm{g}}} U\left(T_{\mathrm{g}}-T_{\mathrm{a}}\right), \\
& E_{\mathrm{c}}=\min \left\{f_{\mathrm{cw}} \rho_{\mathrm{a}} C_{H_{\mathrm{c}}} U\left(Q_{\mathrm{sat}}\left(T_{\mathrm{c}}, P_{\mathrm{a}}\right)-Q\right), E_{\mathrm{c}, \max }\right\}, \\
& E_{\mathrm{t}}=\left\{\begin{array}{l}
\min \left\{\left(1-f_{\mathrm{cw}}\right) \rho_{\mathrm{a}} C_{E_{\mathrm{c}}} U\left(Q_{\mathrm{sat}}\left(T_{\mathrm{c}}, P_{\mathrm{a}}\right)-Q\right), E_{\mathrm{t}, \max }\right\}, \\
\quad\left(\text { if } Q_{\mathrm{sat}}\left(T_{\mathrm{c}}, P_{\mathrm{a}}\right)>Q\right) \\
\left(1-f_{\mathrm{cw}}\right) \rho_{\mathrm{a}} C_{H_{\mathrm{c}}} U\left(Q_{\mathrm{sat}}\left(T_{\mathrm{c}}, P_{\mathrm{a}}\right)-Q\right), \\
\quad \text { (otherwise) }
\end{array}\right. \\
& E_{\mathrm{g}}=\left\{\begin{array}{l}
\min \left\{\rho_{\mathrm{a}} C_{E_{\mathrm{g}}} U\left(h_{\mathrm{ms}} Q_{\mathrm{sat}}\left(T_{\mathrm{g}}, P_{\mathrm{a}}\right)-Q\right), E_{\mathrm{g}, \max }\right\}, \\
\quad\left(\text { if } h_{\mathrm{s}} Q_{\mathrm{sat}}\left(T_{\mathrm{g}}, P_{\mathrm{a}}\right)>Q\right) \\
\rho_{\mathrm{a}} C_{H_{\mathrm{g}}} U\left(h_{\mathrm{ms}} Q_{\mathrm{sat}}\left(T_{\mathrm{g}}, P_{\mathrm{a}}\right)-Q\right), \\
\quad(\text { otherwise })
\end{array}\right. \\
& G_{\mathrm{gs}}=k_{\mathrm{W}}\left(T_{\mathrm{g}}-T_{\mathrm{s}}(0)\right) / d_{\mathrm{w}}, \\
& S_{\mathrm{tw}}= \begin{cases}c_{\mathrm{pw}} \rho_{\mathrm{w}} d_{\mathrm{w}}\left(\mathrm{d} T_{\mathrm{g}} / \mathrm{d} t\right), & \text { (flooded), } \\
0 & \text { (unflooded) }\end{cases}
\end{aligned}
$$


Table 4. Variables.

\begin{tabular}{|c|c|c|c|}
\hline Symbol & Units & Eq. & Description \\
\hline $\bar{A}_{\mathrm{g}, x}$ & $\operatorname{mol}\left(\mathrm{CO}_{2}\right) \mathrm{m}^{-2}(l) \mathrm{s}^{-1}$ & 68 & gross primary production per unit leaf area of sunlit $\left(\bar{A}_{\mathrm{g}, \mathrm{sn}}\right)$ and $\operatorname{shade}\left(\bar{A}_{\mathrm{g}, \mathrm{sh}}\right)$ leaves \\
\hline $\bar{A}_{\mathrm{g}^{\prime}, x}$ & $\operatorname{mol}\left(\mathrm{CO}_{2}\right) \mathrm{m}^{-2}(l) \mathrm{s}^{-1}$ & 72 & $\begin{array}{l}\text { gross primary production without photosynthesis down-regulation per unit leaf area of sunlit } \\
\left(\bar{A}_{\mathrm{g}^{\prime}, \mathrm{sn}}\right) \text { and shade }\left(\bar{A}_{\mathrm{g}^{\prime}, \mathrm{sh}}\right) \text { leaves }\end{array}$ \\
\hline$A_{\mathrm{n}}$ & $\operatorname{mol}\left(\mathrm{CO}_{2}\right) \mathrm{m}^{-2} \mathrm{~s}^{-1}$ & 63 & net carbon assimilation \\
\hline $\bar{A}_{\mathrm{n}, x}$ & $\operatorname{mol}\left(\mathrm{CO}_{2}\right) \mathrm{m}^{-2}(l) \mathrm{s}^{-1}$ & 64 & net carbon assimilation per unit leaf area of sunlit $\left(\bar{A}_{\mathrm{n}, \mathrm{sn}}\right)$ and shade $\left(\bar{A}_{\mathrm{n}, \mathrm{sh}}\right)$ leaves \\
\hline$A_{3, i}$ & - & $\mathrm{C} 8$ & variable for the calculation of coefficients of radiation equations (Eqs. C2 and C3) \\
\hline$A^{+}$ & - & E6 & intermediate variable for the calculation of roughness \\
\hline$C_{E}$ & - & 28 & BTC for latent heat between the entire surface and atmosphere \\
\hline$C_{E_{\mathrm{c}}}$ & - & 25 & BTC for latent heat between canopy and atmosphere \\
\hline$C_{E_{\mathrm{g}}}^{L_{\mathrm{c}}}$ & - & 24 & BTC for latent heat between surface and atmosphere \\
\hline$C_{H}$ & - & 29 & BTC for sensible heat between the entire surface and atmosphere \\
\hline$C_{H_{\mathrm{c}}}$ & - & 27 & BTC for sensible heat between canopy and atmosphere \\
\hline$C_{H_{\mathrm{g}}}$ & - & 26 & BTC for sensible heat between surface and atmosphere \\
\hline$C_{M}$ & - & 38 & BTC for momentum between the entire surface and atmosphere \\
\hline$C_{M \mathrm{~g}}$ & - & 39 & BTC for momentum between surface and atmosphere \\
\hline$C_{x, i}$ & - & $\mathrm{C} 2$ to $\mathrm{C} 5$ & coefficients of radiation equations (Eqs. $12-14 ; x=1,2,3,4$ ) \\
\hline$C_{X}^{0}$ & - & E7 & intermediate variable for the calculation of roughness ( $X$ denotes $T$ or $Q$ ) \\
\hline$C_{X}^{\infty}$ & - & E8 & intermediate parameter for the calculation of roughness ( $X$ denotes $T$ or $Q$ ) \\
\hline$c_{\mathrm{a}}{ }^{\mathrm{C}}$ & $\mathrm{Pa}$ & 98 & partial pressure of atmospheric $\mathrm{CO}_{2}$ \\
\hline$c_{\mathrm{e}}$ & - & E15 & leaf transfer coefficient for specific humidity \\
\hline$c_{\mathrm{hs}}(z)$ & $\mathrm{J} \mathrm{m}^{-3} \mathrm{~K}^{-1}$ & 50 & volumetric heat capacity of soil at a depth of $z$ \\
\hline$c_{\mathrm{i}, x}$ & $\mathrm{~Pa}$ & 64 to 107 & partial pressure of intercellular $\mathrm{CO}_{2}$ \\
\hline$c_{\mathrm{s}, x}$ & $\mathrm{~Pa}$ & 97 & partial pressure of $\mathrm{CO}_{2}$ at leaf boundary \\
\hline$D_{i}^{\mathrm{d}}(l)$ & $\mathrm{W} \mathrm{m}^{-2}$ & 12 & $\begin{array}{l}\text { radiant flux density for downward direct radiation for PAR }(i=1) \text { or NIR }(i=2) \text { at a leaf area } \\
\text { index (LAI) depth of } l\end{array}$ \\
\hline$D_{\mathrm{g}}$ & $\mathrm{kg} \mathrm{m}^{-2} \mathrm{~s}^{-1}$ & 44 & amount of water that falls from canopy onto surface due to gravity \\
\hline$D_{\text {oy }}$ & day & - & the number of days from 1 January \\
\hline$D_{\mathrm{vr}}$ & $\mathrm{K}$ & 112 & development rate at $t$ \\
\hline$D_{\mathrm{vs}}$ & - & 110 & development stage at $t$ \\
\hline$d$ & $\mathrm{~m}$ & E1 & zero-plane displacement height \\
\hline$E_{\mathrm{c}}$ & $\mathrm{kg} \mathrm{m}^{-2} \mathrm{~s}^{-1}$ & 7 & evaporation from canopy \\
\hline$E_{\mathrm{c}, \max }$ & $\mathrm{kg} \mathrm{m}^{-2} \mathrm{~s}^{-1}$ & 7 & maximum evaporation from canopy \\
\hline$E_{\mathrm{g}}$ & $\mathrm{kg} \mathrm{m}^{-2} \mathrm{~s}^{-1}$ & 9 & evaporation from surface \\
\hline$E_{\mathrm{g}, \max }$ & $\mathrm{kg} \mathrm{m}^{-2} \mathrm{~s}^{-1}$ & 62 & maximum evaporation from surface \\
\hline$E_{\mathrm{t}}$ & $\mathrm{kg} \mathrm{m}^{-2} \mathrm{~s}^{-1}$ & 8 & transpiration from canopy \\
\hline$E_{\mathrm{t}, \max }$ & $\mathrm{kg} \mathrm{m}^{-2} \mathrm{~s}^{-1}$ & 61 & maximum transpiration from canopy \\
\hline$e_{\mathrm{a}}$ & $\mathrm{Pa}$ & 105 & atmospheric vapour pressure \\
\hline$e_{\mathrm{i}}$ & $\mathrm{Pa}$ & 106 & vapour pressure in leaf \\
\hline$e_{\text {sat }}$ & $\mathrm{Pa}$ & 107 & saturated vapour pressure \\
\hline$e_{\mathrm{S}, x}$ & $\mathrm{~Pa}$ & 103 & vapour pressure at leaf boundary in sunlit $\left(e_{\mathrm{S}, \mathrm{sn}}\right)$ and shade $\left(e_{\mathrm{S}, \mathrm{sh}}\right)$ leaves \\
\hline$F_{\mathrm{c}}$ & $\mathrm{kg} \mathrm{m}^{-2} \mathrm{~s}^{-1}$ & 46 & amount of water that falls from the canopy onto soil in the case of non-flooded surface \\
\hline$F_{\mathrm{S}}(z)$ & $\mathrm{m}^{3} \mathrm{~m}^{-2} \mathrm{~s}^{-1}$ & 55 & water flux at a soil depth of $z$ \\
\hline$F_{X}$ & - & E9 & intermediate parameter for the calculation of roughness ( $X$ denotes $T$ or $Q$ ) \\
\hline$f_{\mathrm{cW}}$ & - & 40 & fraction of canopy that is wet \\
\hline$f_{\mathrm{df}}$ & - & 17 & fraction of scattered radiation \\
\hline$f_{\text {dwn }}$ & - & 69 & factor of photosynthesis down regulation \\
\hline$f_{\text {int }}$ & - & 43 & interception efficiency of precipitation by canopy \\
\hline$f_{\mathrm{r}}(z)$ & - & 59 & root distribution at a soil depth of $z$ \\
\hline$f_{\mathrm{s}}(z)$ & - & 79 & water stress function on photosynthesis at a soil depth of $z$ \\
\hline$f_{\mathrm{V}}$ & - & 78 & water stress factor on photosynthesis \\
\hline$G_{\mathrm{ds}}$ & $\mathrm{Ks}$ & 111 & growing degree seconds at $t$ \\
\hline$G_{\mathrm{p}, \mathrm{glu}}$ & $\mathrm{kg} \mathrm{ha}^{-1} \mathrm{~s}^{-1}$ & 127 and 129 & glucose partitioned to each organ \\
\hline$G_{\mathrm{r}, \mathrm{glu}}$ & $\mathrm{kg} \mathrm{ha}^{-1} \mathrm{~s}^{-1}$ & 127 and 129 & growth rate of glucose reserves in leaves \\
\hline$G_{\mathrm{r}, \mathrm{pnc}}$ & $\mathrm{kg} \mathrm{ha}^{-1} \mathrm{~s}^{-1}$ & 124 and 128 & growth rate of dry weight for panicles \\
\hline$G_{\mathrm{r}, \text { rot }}$ & $\mathrm{kg} \mathrm{ha}^{-1} \mathrm{~s}^{-1}$ & 125 and 128 & growth rate of dry weight for roots \\
\hline$G_{\mathrm{r}, \text { lef }}$ & $\mathrm{kg} \mathrm{ha}^{-1} \mathrm{~s}^{-1}$ & 122 and 128 & growth rate of dry weight for leaves \\
\hline$G_{\mathrm{r}, \mathrm{stc}}$ & $\mathrm{kg} \mathrm{ha}^{-1} \mathrm{~s}^{-1}$ & 126 and 128 & growth rate of dry weight for starch reserves in stems \\
\hline$G_{\mathrm{r}, \mathrm{stm}}$ & $\mathrm{kg} \mathrm{ha}^{-1} \mathrm{~s}^{-1}$ & 123 and 128 & growth rate of dry weight for stems \\
\hline$G_{\mathrm{S}}(z)$ & $\mathrm{W} \mathrm{m}^{-2}$ & 49 & heat flux at a soil depth of $z$ \\
\hline$G_{\mathrm{gs}}$ & $\mathrm{W} \mathrm{m}^{-2}$ & 10 & heat flux from surface to soil \\
\hline
\end{tabular}


Table 4. Continued.

\begin{tabular}{|c|c|c|c|}
\hline Symbol & Units & Eq. & Description \\
\hline$\overline{g_{\mathrm{a}}}$ & $\mathrm{ms}^{-1}$ & 100 & leaf boundary conductance per unit leaf area for both sides of the leaf \\
\hline $\bar{g}_{1}$ & $\mathrm{~mol} \mathrm{~m}^{-2}(l) \mathrm{s}^{-1}$ & 99 & leaf boundary conductance for vapour per unit leaf area \\
\hline $\bar{g}_{\mathrm{s}}$ & $\mathrm{m} \mathrm{s}^{-1}$ & 108 & stomatal conductance per unit leaf area for both sides of the leaf \\
\hline $\bar{g}_{\mathrm{st}}$ & $\mathrm{mol} \mathrm{m}^{-2}(l) \mathrm{s}^{-1}$ & 109 & stomatal conductance for vapour per unit leaf area for both sides of the leaf \\
\hline $\bar{g}_{\text {st }, x}$ & $\mathrm{~mol} \mathrm{~m}^{-2}(l) \mathrm{s}^{-1}$ & 101 & stomatal conductance for vapour per unit leaf area in sunlit $\left(\bar{g}_{\mathrm{st}, \mathrm{sn}}\right)$ and shade $\left(\bar{g}_{\mathrm{st}, \mathrm{sh}}\right)$ leaves \\
\hline$H_{\mathrm{c}}$ & $\mathrm{W} \mathrm{m}^{-2}$ & 5 & sensible heat flux from canopy \\
\hline$H_{\mathrm{g}}$ & $\mathrm{W} \mathrm{m}^{-2}$ & 6 & sensible heat flux from surface \\
\hline$h_{\mathrm{gt}}^{0}$ & $\mathrm{~m}$ & 139 & canopy height \\
\hline$h_{\text {arg }}$ & $\mathrm{rad}$ & B3 & hour angle from noon $\left(h_{\mathrm{r}}=12\right)$ \\
\hline$h_{\mathrm{ms}}$ & - & 60 & humidity of topsoil \\
\hline$h_{\mathrm{r}}$ & hour & - & local time at the simulation site \\
\hline$h_{\mathrm{s}, x}$ & $\mathrm{PaPa}^{-1}$ & 102 & relative humidity at leaf boundary in sunlit $\left(h_{\mathrm{s}, \mathrm{sn}}\right)$ and shade $\left(h_{\mathrm{s}, \mathrm{sh}}\right)$ leaves \\
\hline$I_{\mathrm{c}}$ & $\mathrm{kg} \mathrm{m}^{-2} \mathrm{~s}^{-1}$ & 42 & amount of precipitation intercepted by canopy \\
\hline$K(z)$ & $\mathrm{kg} \mathrm{s} \mathrm{m}^{-3}$ & 56 & hydraulic conductivity at a soil depth of $z$ \\
\hline$K_{\mathrm{c}}$ & $\mathrm{Pa}$ & 85 & Michaelis constant for $\mathrm{CO}_{2}$ fixation \\
\hline$K_{\mathrm{e}}(z)$ & - & 52 & Kersten number \\
\hline$K_{\mathrm{O}}$ & $\mathrm{Pa}$ & 86 & Michaelis constant for $\mathrm{O}_{2}$ inhibition \\
\hline$k_{\mathrm{ts}}(z)$ & $\mathrm{W} \mathrm{m}^{-1} \mathrm{~K}^{-1}$ & 51 & thermal conductivity at a soil depth of $z$ \\
\hline$L$ & $\mathrm{~m}^{2} \mathrm{~m}^{-2}$ & 137 & LAI \\
\hline$L_{\mathrm{MO}}$ & $\mathrm{m}$ & 35 & Monin-Obukhov length of the entire surface \\
\hline$L_{\mathrm{MOg}}$ & $\mathrm{m}$ & 36 & Monin-Obukhov length of surface \\
\hline$L_{\mathrm{s}, \text { lef }}$ & $\mathrm{kg} \mathrm{ha}^{-1} \mathrm{~s}^{-1}$ & 133 & loss rate of dry weight for leaves \\
\hline$L_{\mathrm{sn}}$ & $\mathrm{m}^{2}(l) \mathrm{m}^{-2}$ & 65 & LAI for sunlit leaves \\
\hline$L_{\mathrm{sh}}$ & $\mathrm{m}^{2}(l) \mathrm{m}^{-2}$ & 66 & LAI for shade leaves \\
\hline$l$ & $\mathrm{~m}^{2}(l) \mathrm{m}^{-2}$ & - & LAI depth from the top of canopy \\
\hline$P_{\mathrm{r}, \mathrm{sh}}$ & - & 130 & ratio of glucose partitioned to shoot \\
\hline$P_{\mathrm{r}, \mathrm{pnc}}$ & - & 132 & ratio of glucose partitioned to panicle from the glucose partitioned to shoot \\
\hline$P_{\mathrm{r}, \text { lef }}$ & - & 131 & ratio of glucose partitioned to leaf from the glucose partitioned to shoot \\
\hline$P_{1 *}$ & - & E11 & intermediate variable for the calculation of roughness $(*$ denotes $M, T$, or $Q$ ) \\
\hline$P_{2 *}$ & - & E12 & intermediate variable for the calculation of roughness $(*$ denotes $M, T$, or $Q$ ) \\
\hline$P_{3 X}$ & - & E13 & intermediate parameter for the calculation of roughness $(X$ denotes $T$ or $Q$ ) \\
\hline$P_{4 X}$ & - & E13 & intermediate parameter for the calculation of roughness ( $X$ denotes $T$ or $Q$ ) \\
\hline$Q_{\text {sat }}$ & $\mathrm{kg} \mathrm{kg}^{-1}$ & A2 & specific humidity at saturation \\
\hline$Q_{\mathrm{sn}}$ & $\mathrm{mol} \mathrm{m}^{-2} \mathrm{~s}^{-1}$ & 89 & photon flux density for PAR absorbed by canopy in sunlit leaves \\
\hline$Q_{\text {sn,d }}$ & $\mathrm{mol} \mathrm{m}^{-2} \mathrm{~s}^{-1}$ & 91 & direct PAR absorbed in sunlit leaves \\
\hline$Q_{\text {sn, s }}$ & $\mathrm{mol} \mathrm{m}^{-2} \mathrm{~s}^{-1}$ & 92 & scattered PAR absorbed in shade leaves \\
\hline$Q_{\mathrm{sh}}$ & $\mathrm{mol} \mathrm{m}^{-2} \mathrm{~s}^{-1}$ & 90 & photon flux density for PAR absorbed by canopy in shade leaves \\
\hline$Q_{\text {sh, s }}$ & $\mathrm{mol} \mathrm{m}^{-2} \mathrm{~s}^{-1}$ & 93 & scattered PAR absorbed in shade leaves \\
\hline $\bar{Q}_{x}$ & $\mathrm{~mol} \mathrm{~m}^{-2}(l) \mathrm{s}^{-1}$ & 88 & photon flux density for PAR absorbed by leaves in sunlit $\left(\bar{Q}_{\mathrm{sn}}\right)$ and shade $\left(\bar{Q}_{\mathrm{sh}}\right)$ leaves \\
\hline$q_{\mathrm{t}}$ & - & 80 & function that represents temperature dependence \\
\hline $\bar{R}_{\mathrm{d}, x}$ & $\operatorname{mol}\left(\mathrm{CO}_{2}\right) \mathrm{m}^{-2}(l) \mathrm{s}^{-1}$ & 94 & respiration in sunlit $\left(\bar{R}_{\mathrm{d}, \mathrm{sn}}\right)$ and shade $\left(\bar{R}_{\mathrm{d}, \mathrm{sh}}\right)$ leaves \\
\hline$R_{\mathrm{ex}}$ & $\mathrm{W} \mathrm{m}^{-2}$ & 19 & extraterrestrial radiation \\
\hline$R_{\mathrm{m}, \mathrm{stc}}$ & $\mathrm{kg} \mathrm{ha}^{-1} \mathrm{~s}^{-1}$ & 134 & remobilization rate of dry weight from starch reserves \\
\hline$R_{\mathrm{nc}}$ & $\mathrm{W} \mathrm{m}^{-2}$ & 3 & net radiant flux density at canopy \\
\hline$R_{\mathrm{ng}}$ & $\mathrm{W} \mathrm{m}^{-2}$ & 4 & net radiant flux density at surface \\
\hline$R_{1}^{\mathrm{d}}(l)$ & $\mathrm{W} \mathrm{m}^{-2}$ & 21 & radiant flux density for downward longwave at a LAI depth of $l$ \\
\hline$R_{\mathrm{S}}^{\mathrm{d}}(l)$ & $\mathrm{W} \mathrm{m}^{-2}$ & 21 & radiant flux density for downward shortwave at a LAI depth of $l$ \\
\hline$R_{\mathrm{S}}^{\mathrm{u}}(l)$ & $\mathrm{W} \mathrm{m}^{-2}$ & 21 & radiant flux density for upward shortwave at a LAI depth of $l$ \\
\hline$r_{\mathrm{dd}, \text { lef }}$ & $\mathrm{s}^{-1}$ & 135 & ratio of dead leaf \\
\hline$r_{i j}$ & - & D1 and D2 & reflectivity of canopies ( $i=1: \mathrm{PAR} ; i=2: \mathrm{NIR} ; j=1:$ direct; $j=2:$ scattered) \\
\hline$r_{\mathrm{S}}$ & - & 30 & resistance of topsoil to evaporation \\
\hline$S$ & - & 87 & Ratio of RuBP partitioned to carboxylase or oxygenase \\
\hline$S_{i}^{\mathrm{d}}(l)$ & $\mathrm{W} \mathrm{m}^{-2}$ & 13 & $\begin{array}{l}\text { radiant flux density for downward scattered radiation for } \operatorname{PAR}(i=1) \text { or NIR }(i=2) \text { at a } \\
\text { LAI depth of } l\end{array}$ \\
\hline$S_{i}^{\mathrm{u}}(l)$ & $\mathrm{W} \mathrm{m}^{-2}$ & 14 & $\begin{array}{l}\text { radiant flux density for upward scattered radiation for PAR }(i=1) \text { or NIR }(i=2) \text { at a LAI } \\
\text { depth of } l\end{array}$ \\
\hline$S_{\text {glu }}$ & $\mathrm{kg} \mathrm{ha}^{-1} \mathrm{~s}^{-1}$ & 119 & supply of glucose to the reserves in leaf \\
\hline$S_{\mathrm{lW}}$ & $\mathrm{kg} \mathrm{m}^{-2}(l)$ & 138 & specific leaf area \\
\hline$S_{\mathrm{s}}(z)$ & $\mathrm{m}^{3} \mathrm{~m}^{-3} \mathrm{~s}^{-1}$ & 58 & absorption for transpiration by root at a soil depth of $z$ \\
\hline$S_{\mathrm{tw}}$ & $\mathrm{W} \mathrm{m}^{-2}$ & 11 & heat flux stored in surface water \\
\hline
\end{tabular}


Table 4. Continued.

\begin{tabular}{|c|c|c|c|}
\hline Symbol & Units & Eq. & Description \\
\hline$T_{\mathrm{c}}$ & $\mathrm{K}$ & 3 to 11 & canopy temperature \\
\hline$T_{\mathrm{S}}(z)$ & $\mathrm{K}$ & 48 & soil temperature at a soil depth of $z$ \\
\hline$T_{x}$ & $\mathrm{~K}$ & A2 & temperature of canopy $\left(T_{\mathrm{c}}\right)$ or surface $\left(T_{\mathrm{g}}\right)$ \\
\hline$T_{\mathrm{g}}$ & $\mathrm{K}$ & 3 to 11 & surface temperature \\
\hline$t^{0}$ & $\mathrm{~s}$ & - & time \\
\hline$t_{\mathrm{e}}$ & $\mathrm{s}$ & - & time at emergence after sowing \\
\hline$U_{\mathrm{c}}$ & $\mathrm{ms}^{-1}$ & $\mathrm{~F} 1$ & wind speed in the canopy \\
\hline$U_{\mathrm{h}}$ & $\mathrm{ms}^{-1}$ & $\mathrm{~F} 2$ & reference wind speed \\
\hline$V_{\max }(l)$ & $\operatorname{mol}\left(\mathrm{CO}_{2}\right) \mathrm{m}^{-2}(l) \mathrm{s}^{-1}$ & 83 & reference value for maximum RuBisCO capacity at a LAI depth of $l$ \\
\hline $\bar{V}_{\max , x}$ & $\operatorname{mol}\left(\mathrm{CO}_{2}\right) \mathrm{m}^{-2}(l) \mathrm{s}^{-1}$ & 81 and 82 & reference value for maximum RuBisCO capacity per unit leaf area of sunlit and shade leaves \\
\hline $\bar{V}_{\mathrm{mc}, x}$ & $\operatorname{mol}\left(\mathrm{CO}_{2}\right) \mathrm{m}^{-2}(l) \mathrm{s}^{-1}$ & 76 & $\begin{array}{l}\text { maximum RuBisCO capacity per unit leaf area of sunlit }\left(\bar{V}_{\mathrm{mc}, \mathrm{sn}}\right) \text { and shade }\left(\bar{V}_{\mathrm{mc}, \mathrm{sh}}\right) \\
\text { leaves for } \bar{\omega}_{\mathrm{c}, x}\end{array}$ \\
\hline $\bar{V}_{\mathrm{ms}, x}$ & $\operatorname{mol}\left(\mathrm{CO}_{2}\right) \mathrm{m}^{-2}(l) \mathrm{s}^{-1}$ & 77 & $\begin{array}{l}\text { maximum RuBisCO capacity per unit leaf area of sunlit }\left(\bar{V}_{\mathrm{ms}, \mathrm{sn}}\right) \text { and shade }\left(\bar{V}_{\mathrm{ms}, \mathrm{sh}}\right) \\
\text { leaves for } \bar{\omega}_{\mathrm{s}, x}\end{array}$ \\
\hline$W_{\text {glu }}$ & $\mathrm{kg} \mathrm{ha}^{-1}$ & 118 & dry weight of glucose reserves in leaves \\
\hline$W_{\mathrm{pnc}}$ & $\mathrm{kg} \mathrm{ha}^{-1}$ & 115 & dry weight of panicles \\
\hline$W_{\text {pnc, mt }}$ & $\mathrm{kg} \mathrm{ha}^{-1}$ & - & dry weight of panicles at maturity \\
\hline$W_{\text {rot }}$ & $\mathrm{kg} \mathrm{ha}^{-1}$ & 116 & dry weight of roots \\
\hline$W_{\mathrm{sh}}$ & $\mathrm{kg} \mathrm{ha}^{-1}$ & 136 & dry weight of shoot \\
\hline$W_{\text {stc }}$ & $\mathrm{kg} \mathrm{ha}^{-1}$ & 117 & dry weight of starch reserves in stems \\
\hline$W_{\mathrm{stm}}$ & $\mathrm{kg} \mathrm{ha}^{-1}$ & 114 & dry weight of stems \\
\hline$w_{\mathrm{c}}$ & $\mathrm{m}$ & 41 & amount of water stored in canopy \\
\hline$w_{\text {cap }}$ & $\mathrm{m}$ & 45 & canopy water capacity \\
\hline$w_{\mathrm{s}}(z)$ & $\mathrm{m}^{3} \mathrm{~m}^{-3}$ & 53 & volumetric concentration of soil water at a soil depth of $z$ \\
\hline$Y_{\mathrm{ld}}$ & $\mathrm{kg} \mathrm{ha}^{-1}$ & 141 & crop yield \\
\hline$z$ & $\mathrm{~m}$ & - & soil depth \\
\hline$z_{M}$ & $\mathrm{~m}$ & E2 & roughness length of the entire surface for momentum profile \\
\hline$z_{M g}$ & $\mathrm{~m}$ & E4 & roughness length that express the effect of water surface on the profile of momentum \\
\hline$z_{M}^{+}$ & $\mathrm{m}$ & E10 & intermediate variable for the calculation of roughness \\
\hline$z_{Q}$ & $\mathrm{~m}$ & E3 & roughness length of the entire surface for specific humidity profile \\
\hline$z_{\mathrm{rt}}$ & $\mathrm{m}$ & 140 & root depth \\
\hline$z_{T}$ & $\mathrm{~m}$ & E3 & roughness length of the entire surface for temperature profile \\
\hline$z_{T g}$ & $\mathrm{~m}$ & E5 & roughness length that express the effect of water surface on the profile of temperature \\
\hline$z_{X}^{+}$ & $\mathrm{m}$ & E10 & intermediate variable for the calculation of roughness ( $X$ denotes $T$ or $Q$ ) \\
\hline$z_{*}^{+}$ & $\mathrm{m}$ & E10 & intermediate variable for the calculation of roughness ( $*$ denotes $M, T$, or $Q$ ) \\
\hline$\delta_{\mathrm{s}}$ & $\mathrm{rad}$ & B2 & declination of the sun \\
\hline$\Gamma^{*}$ & $\mathrm{~Pa}$ & 84 & light compensation point \\
\hline$\gamma_{\mathrm{m}}$ & - & F3 & coefficient of exponential decrease for wind speed in the canopy \\
\hline $\bar{\omega}_{\mathrm{c}, x}$ & $\operatorname{mol}\left(\mathrm{CO}_{2}\right) \mathrm{m}^{-2}(l) \mathrm{s}^{-1}$ & 73 & RuBisCO-limited assimilation in sunlit $\left(\bar{\omega}_{\mathrm{c}, \mathrm{sn}}\right)$ and shade $\left(\bar{\omega}_{\mathrm{c}, \mathrm{sh}}\right)$ leaves \\
\hline $\bar{\omega}_{\mathrm{e}, x}$ & $\operatorname{mol}\left(\mathrm{CO}_{2}\right) \mathrm{m}^{-2}(l) \mathrm{s}^{-1}$ & 74 & light-limited assimilation in sunlit $\left(\bar{\omega}_{\mathrm{e}, \mathrm{sn}}\right)$ and shade $\left(\bar{\omega}_{\mathrm{e}, \mathrm{sh}}\right)$ leaves \\
\hline $\bar{\omega}_{\mathrm{p}, x}$ & $\operatorname{mol}\left(\mathrm{CO}_{2}\right) \mathrm{m}^{-2}(l) \mathrm{s}^{-1}$ & 71 & RuBisCO- and light-limited assimilation in sunlit $\left(\bar{\omega}_{\mathrm{p}, \mathrm{sn}}\right)$ and shade $\left(\bar{\omega}_{\mathrm{p}, \mathrm{sh}}\right)$ leaves \\
\hline $\bar{\omega}_{\mathrm{s}, x}$ & $\operatorname{mol}\left(\mathrm{CO}_{2}\right) \mathrm{m}^{-2}(l) \mathrm{s}^{-1}$ & 75 & sucrose limited assimilation for sunlit $\left(\bar{\omega}_{\mathrm{s}, \mathrm{sn}}\right)$ and shade $\left(\bar{\omega}_{\mathrm{s}, \mathrm{sh}}\right)$ leaves \\
\hline$\Psi_{E}$ & - & 32 & diabatic correction factor for vapour \\
\hline$\Psi_{H}$ & - & 32 & diabatic correction factor for heat \\
\hline$\Psi_{M}$ & - & 31 & diabatic correction factor for momentum \\
\hline$\psi(z)$ & $\mathrm{J} \mathrm{kg}^{-1}$ & 57 & water potential at a soil depth of $z$ \\
\hline$\rho_{\mathrm{a}}$ & $\mathrm{kg} \mathrm{m}^{-3}$ & A1 & air density \\
\hline$\tau_{\mathrm{atm}}$ & - & 18 & transmissivity of atmosphere \\
\hline$\tau_{\mathrm{cs}}$ & - & 20 & transmissivity of canopy for shortwave radiation \\
\hline$\tau_{\mathrm{cl}}$ & - & 23 & transmissivity of canopy for longwave radiation \\
\hline$\tau_{i j}$ & - & D3 and D4 & transmissivity of canopy ( $i=1: \mathrm{PAR} ; i=2: \mathrm{NIR} ; j=1:$ direct; $j=2:$ scattered) \\
\hline$\Theta_{0}$ & $\mathrm{~K}$ & 37 & potential temperature \\
\hline$\theta$ & $\mathrm{rad}$ & B1 & zenith angle of the sun \\
\hline$\zeta$ & - & 33 & atmospheric stability between the entire canopy and atmosphere \\
\hline$\zeta_{\mathrm{g}}$ & - & 34 & atmospheric stability between surface and atmosphere \\
\hline
\end{tabular}


Table 5. Physical and chemical constants.

\begin{tabular}{lrll}
\hline Variable & Value & Units & Description \\
\hline$C_{\mathrm{CO}_{2}, \text { glu }}$ & $1.08 \times 10^{6}$ & $\mathrm{~kg} \mathrm{ha}^{-1} \mathrm{~h}^{-1} /\left(\mathrm{mol} \mathrm{m}^{-2} \mathrm{~s}^{-1}\right)$ & conversion factor from $\mathrm{CO}_{2}$ to glucose \\
$C_{\mathrm{glu}, \mathrm{stc}}$ & 0.9 & $\mathrm{~kg} \mathrm{ha}^{-1} /\left(\mathrm{kg} \mathrm{ha}^{-1}\right)$ & conversion factor of dry weight from glucose to starch \\
$C_{\text {stc,glu }}$ & 1.11 & $\mathrm{~kg} \mathrm{ha}^{-1} /\left(\mathrm{kg} \mathrm{ha}^{-1}\right)$ & conversion factor of dry weight from starch to glucose \\
$c_{\mathrm{pa}}$ & 1004.6 & $\mathrm{~J} \mathrm{~K}^{-1} \mathrm{~kg}^{-1}$ & specific heat of air \\
$c_{\mathrm{pw}}$ & 4200 & $\mathrm{~J} \mathrm{~K}^{-1} \mathrm{~kg}^{-1}$ & specific heat of water \\
$g$ & 9.8 & $\mathrm{~m} \mathrm{~s}^{-1}$ & gravitational constant \\
$e_{\mathrm{Sat}}\left(T_{0}\right)$ & 611 & $\mathrm{~Pa}_{\mathrm{q}}$ & vapour pressure at melting temperature of water \\
$k_{\mathrm{q}}$ & $4.6 \times 10^{-6}$ & $\left(\mathrm{~mol} \mathrm{~m}^{-2} \mathrm{~s}^{-1}\right) /\left(\mathrm{W} \mathrm{m} \mathrm{m}^{-2}\right)$ & transfer constant from radiant flux density to photon flux density \\
$k_{\mathrm{W}}$ & 0.6 & $\mathrm{~W} \mathrm{~m}^{-1} \mathrm{~K}^{-1}$ & thermal conductivity of water \\
$R_{\mathrm{dry}}$ & 287.04 & $\mathrm{~J} \mathrm{~kg}^{-1} \mathrm{~K}^{-1}$ & gas constant of dry air \\
$R_{\mathrm{sun}}$ & 1370 & $\mathrm{~W} \mathrm{~m}^{-2}$ & solar constant \\
$R_{\mathrm{vap}}$ & 461 & $\mathrm{~J} \mathrm{~kg}^{-1} \mathrm{~K}^{-1}$ & gas constant of vapour \\
$T_{0}$ & 273.15 & $\mathrm{~K}$ & melting temperature of water \\
$w_{\mathrm{H}} \mathrm{O}$ & 0.018 & $\mathrm{~kg} \mathrm{~mol}^{-1}$ & molar weight of vapour \\
$\kappa$ & 0.4 & - & Karman constant \\
$\lambda$ & $2.5 \times 10^{6}$ & $\mathrm{~J} \mathrm{~kg}^{-1}$ & latent heat of vaporization \\
$\rho_{\mathrm{W}}$ & 1000 & $\mathrm{~kg} \mathrm{~m}^{-3}$ & water density \\
$\sigma$ & $5.67 \times 10^{-8}$ & $\mathrm{~W} \mathrm{~m}^{-2} \mathrm{~K}^{-4}$ & Boltzmann constant \\
\hline & & &
\end{tabular}

where $R_{\mathrm{S}}^{\mathrm{d}}(0), R_{1}^{\mathrm{d}}(0)$, and $R_{\mathrm{s}}^{\mathrm{u}}(0)$ are the downward shortwave radiant flux density, downward longwave radiant flux density, and upward shortwave radiant flux density at the canopy top, respectively; $\tau_{\mathrm{cs}}$ and $\tau_{\mathrm{cl}}$ are the canopy transmissivity for shortwave and longwave radiation, respectively; $C_{H_{\mathrm{c}}}$ and $C_{H_{\mathrm{g}}}$ are the bulk transfer coefficients (BTCs) for sensible heat between canopy and atmosphere and between surface and atmosphere, respectively; $C_{E_{\mathrm{c}}}$ and $C_{E_{\mathrm{g}}}$ are the BTCs for latent heat between canopy and atmosphere and between surface and atmosphere, respectively; $T_{\mathrm{a}}, P_{\mathrm{a}}, U$, and $Q$ are air temperature, air pressure, wind speed, and specific humidity, respectively; $f_{\mathrm{cw}}$ is the fraction of wet canopy; $h_{\mathrm{ms}}$ is humidity of the topsoil; $T_{\mathrm{c}}, T_{\mathrm{g}}$, and $T_{\mathrm{s}}(0)$ are the canopy, surface, and topsoil temperature, respectively; $E_{\mathrm{t}, \max }, E_{\mathrm{g}, \max }$, and $E_{\mathrm{c}, \max }$ are the maximum transpiration from canopy, the maximum evaporation from surface, and the maximum evaporation from the canopy, respectively; $c_{\mathrm{pa}}$ and $c_{\mathrm{pw}}$ are the specific air and water heat, respectively; $k_{\mathrm{w}}$ is the water thermal conductivity; $\rho_{\mathrm{w}}$ and $\rho_{\mathrm{a}}$ are water and air density, respectively; $\sigma$ is the Boltzmann constant; $Q_{\text {sat }}$ is specific humidity at saturation; $d_{\mathrm{w}}$ is the depth of surface water in the case of flooded surface; $\epsilon$ is the longwave emissivity of surface; and $d / \mathrm{d} t$ indicates the time differentiation. The argument of the radiant flux density denotes LAI depth from the canopy top, and the argument of soil temperature denotes soil depth from the soil surface. Therefore, $R_{\mathrm{s}}^{\mathrm{d}}(0), R_{1}^{\mathrm{d}}(0)$, and $R_{\mathrm{s}}^{\mathrm{u}}(0)$ indicate the radiant flux density at the canopy top, and $T_{\mathrm{S}}(0)$ indicates the soil surface temperature.

$T_{\mathrm{a}}, P_{\mathrm{a}}, U, Q, R_{\mathrm{s}}^{\mathrm{d}}(0)$, and $R_{1}^{\mathrm{d}}(0)$ are meteorological forcing inputs (Table 1). $R_{\mathrm{s}}^{\mathrm{u}}(0), \tau_{\mathrm{cs}}, \tau_{\mathrm{cl}}, f_{\mathrm{cw}}, h_{\mathrm{ms}}, C_{E_{\mathrm{c}}}, C_{E_{\mathrm{g}}}$, $C_{H_{\mathrm{c}}}, C_{H_{\mathrm{g}}}, T_{\mathrm{s}}(0), E_{\mathrm{t}, \max }, E_{\mathrm{g}, \max }$, and $E_{\mathrm{c}, \max }$ are calculated from Eqs. (21), (20), (23), (40), (60), (25), (24), (27), (26), (48), (61), (62), and (47), respectively, which are given in the following sections. The variables $\rho_{\mathrm{a}}$ and $Q_{\text {sat }}$ are physically calculated from the air temperature and air pressure (Appendix A); $c_{\mathrm{pa}}, c_{\mathrm{pw}}, k_{\mathrm{w}}, \rho_{\mathrm{w}}$, and $\sigma$ are physical constants (Table 5); $d_{\mathrm{W}}$ is a simulation setting parameter (Table 6); and $\epsilon$ is set to 0.96 (Campbell and Norman, 1998). $T_{\mathrm{c}}$ and $T_{\mathrm{g}}$ are numerically determined to satisfy Eqs. (1)-(11). The numerical method is described in Masutomi et al. (2016).

Irrigation and flooded surface start at $D_{\text {oy,Is }}$ and end at $D_{\text {oy,Ie. }} D_{\text {oy,Is }}$ and $D_{\text {oy,Ie }}$ are simulation setting parameters.

\subsection{Within-canopy shortwave radiation}

The main role of this module is to simulate direct downward photosynthesis active radiation (PAR), scattered downward PAR, and scattered upward PAR at a LAI depth of $l$ from the canopy top by calculating the transmission and reflection of shortwave radiation by leaves within canopies. These PARs are used for calculating carbon assimilation in the CGM (Sect. 4.1). In addition to the simulation of PARs, transmissivities for shortwave and longwave radiation are simulated in this module. The transmissivities are used for calculating LHF and SHF (Sect 3.1).

This module is based on the simple model developed by Watanabe and Ohtani (1995). The model determines radiation within canopies by calculating the transmission and reflection of the radiation within the canopy. In this model, radiation within the canopy is divided into three components (downward direct, downward scattered, and upward scattered) and two wavebands (PAR and near infrared (NIR)). 
Table 6. Parameters.

\begin{tabular}{|c|c|c|c|c|}
\hline Variable & Value & Units & Description & Source \\
\hline \multicolumn{5}{|c|}{ Simulation setting } \\
\hline$C_{\mathrm{a}, \mathrm{ppm}}$ & - & ppm & atmospheric $\mathrm{CO}_{2}$ concentration & Masutomi et al. (2016) \\
\hline$D_{\text {oy,Ie }}$ & - & DOY & DOY of the day that irrigation and flooded surface end & Masutomi et al. (2016) \\
\hline$D_{\mathrm{Oy}, \mathrm{Is}}$ & - & DOY & DOY of the day that irrigation and flooded surface start & Masutomi et al. (2016) \\
\hline$D_{\mathrm{oy}, \mathrm{sw}}$ & - & DOY & DOY of sowing day & Masutomi et al. (2016) \\
\hline$d_{\mathrm{W}}$ & - & $\mathrm{m}$ & depth of surface water & Masutomi et al. (2016) \\
\hline$L_{\mathrm{t}}$ & - & $\circ$ & latitude of the simulation site & Masutomi et al. (2016) \\
\hline$W_{\text {glu }, 0}$ & - & $\mathrm{kg} \mathrm{ha}^{-1}$ & dry weight of glucose reserve at emergence & Masutomi et al. (2016) \\
\hline$W_{\text {lef, } 0}$ & - & $\mathrm{kg} \mathrm{ha}^{-1}$ & dry weight of leaf at emergence & Masutomi et al. (2016) \\
\hline$W_{\text {rot }, 0}$ & - & $\mathrm{kg} \mathrm{ha}^{-1}$ & dry weight of root at emergence & Masutomi et al. (2016) \\
\hline$W_{\text {stm }, 0}$ & - & $\mathrm{kg} \mathrm{ha}^{-1}$ & dry weight of stem at emergence & Masutomi et al. (2016) \\
\hline$z_{\mathrm{a}}$ & - & $\mathrm{m}$ & reference height at which wind speed is observed & Masutomi et al. (2016) \\
\hline$z_{\max }$ & - & $\mathrm{m}$ & depth of soil layer & Masutomi et al. (2016) \\
\hline$z_{\mathrm{t}}$ & - & $\mathrm{m}$ & depth of the soil surface layer & Masutomi et al. (2016) \\
\hline$z_{\mathrm{b}}$ & - & $\mathrm{m}$ & $\begin{array}{l}\text { depth from the soil surface to the upper bound of the bottom- } \\
\text { most layer of soil }\end{array}$ & Masutomi et al. (2016) \\
\hline$\delta t$ & - & s & time resolution & Masutomi et al. (2016) \\
\hline \multicolumn{5}{|c|}{ Soil-type specific } \\
\hline$B$ & - & - & factor for hydraulic conductivity and water potential & Masutomi et al. (2016) \\
\hline$K_{\mathrm{S}}$ & - & $\mathrm{kg} \mathrm{s} \mathrm{m}^{-3}$ & hydraulic conductivity at saturation & Masutomi et al. (2016) \\
\hline$w_{\text {sat }}$ & - & $\mathrm{m}^{3} \mathrm{~m}^{-3}$ & volumetric concentration of soil water at saturation & Masutomi et al. (2016) \\
\hline$w_{\text {wlt }}$ & - & $\mathrm{m}^{3} \mathrm{~m}^{-3}$ & volumetric concentration of soil water at the wilting point & Masutomi et al. (2016) \\
\hline$\psi_{\mathrm{s}}$ & - & $\mathrm{J} \mathrm{kg}^{-1}$ & water potential at saturation & Masutomi et al. (2016) \\
\hline$\rho_{\mathrm{S}}$ & - & $\mathrm{kg} \mathrm{m}^{-3}$ & soil bulk density & Masutomi et al. (2016) \\
\hline \multicolumn{5}{|c|}{ Crop specific (paddy rice) } \\
\hline$b$ & 0.01 & $\mathrm{~mol} \mathrm{~m}^{-2} \mathrm{~s}^{-1}$ & intercept of the Ball-Berry model & Sellers et al. (1996b) \\
\hline$C_{\text {glu, lef }}$ & 0.955 & $\mathrm{~kg} \mathrm{ha}^{-1} /\left(\mathrm{kg} \mathrm{ha}^{-1}\right)$ & conversion factor of dry weight from glucose to leaf & Penning de Vries et al. (1989) \\
\hline$C_{\mathrm{glu}, \mathrm{pnc}}$ & 0.821 & $\mathrm{~kg} \mathrm{ha}^{-1} /\left(\mathrm{kg} \mathrm{ha}^{-1}\right)$ & conversion factor of dry weight from glucose to panicle & Penning de Vries et al. (1989) \\
\hline$C_{\mathrm{glu}, \text { rot }}$ & 0.928 & $\mathrm{~kg} \mathrm{ha}^{-1} /\left(\mathrm{kg} \mathrm{ha}^{-1}\right)$ & conversion factor of dry weight from glucose to root & Penning de Vries et al. (1989) \\
\hline$C_{\mathrm{glu}, \mathrm{stm}}$ & 0.928 & $\mathrm{~kg} \mathrm{ha}^{-1} /\left(\mathrm{kg} \mathrm{ha}^{-1}\right)$ & conversion factor of dry weight from glucose to stem & Penning de Vries et al. (1989) \\
\hline$c_{\mathrm{h}}$ & 0.06 & - & leaf transfer coefficient for heat & Kimura and Kondo (1998) \\
\hline$c_{\mathrm{m}}$ & 0.2 & - & leaf transfer coefficient for momentum & Kimura and Kondo (1998) \\
\hline$D_{\mathrm{vs}, \text { rot } 1}$ & Parameterized & - & 1st point of $D_{\mathrm{vs}}$ at which the partition to root changes & Masutomi et al. (2016) \\
\hline$D_{\mathrm{vs}, \operatorname{rot} 2}$ & Parameterized & - & 2nd point of $D_{\mathrm{vs}}$ at which the partition to root changes & Masutomi et al. (2016) \\
\hline$D_{\mathrm{vs}, \text { lef1 }}$ & Parameterized & - & 1st point of $D_{\mathrm{vs}}$ at which the partition to leaf changes & Masutomi et al. (2016) \\
\hline$D_{\mathrm{vs}, \text { lef2 }}$ & Parameterized & - & 2nd point of $D_{\mathrm{vs}}$ at which the partition to leaf changes & Masutomi et al. (2016) \\
\hline$D_{\mathrm{vs}, \mathrm{pnc} 1}$ & Parameterized & - & 1st point of $D_{\mathrm{vs}}$ at which the partition to panicle changes & Masutomi et al. (2016) \\
\hline$D_{\mathrm{vs}, \mathrm{pnc} 2}$ & Parameterized & - & 2nd point of $D_{\mathrm{vs}}$ at which the partition to panicle changes & Masutomi et al. (2016) \\
\hline$D_{\mathrm{vs}, \mathrm{e}}$ & Parameterized & - & $D_{\mathrm{vs}}$ at emergence & Masutomi et al. (2016) \\
\hline$f_{\mathrm{d}}$ & 0.015 & - & respiration factor & Sellers et al. (1996b) \\
\hline$f_{\text {stc }}$ & Parameterized & - & fraction of glucose allocated to starch reserves & Masutomi et al. (2016) \\
\hline$h_{\mathrm{aa}}$ & Parameterized & - & $\begin{array}{l}\text { parameter for relation between leaf area index (LAI) and height } \\
\text { before heading }\end{array}$ & Masutomi et al. (2016) \\
\hline$h_{\mathrm{ab}}$ & Parameterized & - & parameter for relation between LAI and height before heading & Masutomi et al. (2016) \\
\hline$h_{\mathrm{ba}}$ & Parameterized & - & parameter for relation between LAI and height after heading & Masutomi et al. (2016) \\
\hline$h_{\mathrm{bb}}$ & Parameterized & - & parameter for relation between LAI and height after heading & Masutomi et al. (2016) \\
\hline$D_{\mathrm{vs}, \mathrm{h}}$ & Parameterized & - & $D_{\text {vs }}$ at heading & Masutomi et al. (2016) \\
\hline$k_{\text {yld }}$ & Parameterized & - & ratio of crop yield to dry weight of panicle at maturity & Masutomi et al. (2016) \\
\hline$k_{S_{\text {lw }}}$ & Parameterized & - & parameter for the relation between $S_{\mathrm{lw}}$ and $D_{\mathrm{vs}}$ & Masutomi et al. (2016) \\
\hline$m$ & 9 & - & the slope of the Ball-Berry model & Sellers et al. (1996b) \\
\hline$G_{\mathrm{ds}, \mathrm{m}}$ & Parameterized & $\mathrm{Ks}$ & growing degree second at maturity & Masutomi et al. (2016) \\
\hline$P_{\text {rot }}$ & Parameterized & - & ratio of glucose partitioned to root & Masutomi et al. (2016) \\
\hline$P_{\text {lef }}$ & Parameterized & - & $\begin{array}{l}\text { ratio of glucose partitioned to leaf from glucose partitioned to } \\
\text { shoot }\end{array}$ & Masutomi et al. (2016) \\
\hline$r_{\mathrm{d} 1, \text { lef }}$ & Parameterized & $\mathrm{s}^{-1}$ & ratio of dead leaf at harvest & Masutomi et al. (2016) \\
\hline$r_{\mathrm{rm}, \mathrm{stc}}$ & $1.16 \times 10^{-6}$ & $s^{-1}$ & ratio of remobilization & Bouman et al. (2001) \\
\hline$r_{\mathrm{rt}}$ & $1.16 \times 10^{-7}$ & $\mathrm{~m} \mathrm{~s}^{-1}$ & growth ratio of root & Penning de Vries et al. (1989) \\
\hline
\end{tabular}


Table 6. Continued.

\begin{tabular}{|c|c|c|c|c|}
\hline Variable & Value & Units & Description & Source \\
\hline$r_{1}$ & 0.105 & - & leaf reflectivity for photosynthesis active radiation (PAR) & Sellers et al. (1996b) \\
\hline$r_{2}$ & 0.58 & - & leaf reflectivity for near infrared radiation (NIR) & Sellers et al. (1996b) \\
\hline$S_{\mathrm{lW}, \mathrm{mx}}$ & Parameterized & $\mathrm{kg} \mathrm{m}^{-2}$ & maximum specific leaf area & Masutomi et al. (2016) \\
\hline$S_{\mathrm{lW}, \mathrm{mn}}$ & Parameterized & $\mathrm{kg} \mathrm{m}^{-2}$ & minimum specific leaf area & Masutomi et al. (2016) \\
\hline$s_{1}$ & Parameterized & $\mathrm{K}^{-1}$ & temperature dependence of $\bar{V}_{\max , x}$ on $\bar{V}_{\mathrm{mc}, x}$ & Masutomi et al. (2016) \\
\hline$s_{2}$ & Parameterized & $\mathrm{K}$ & temperature dependence of $\bar{V}_{\max , x}$ on $\bar{V}_{\mathrm{mc}, x}$ & Masutomi et al. (2016) \\
\hline$s_{4}$ & 281 & $\mathrm{~K}$ & temperature dependence of $\bar{V}_{\max , x}$ on $\bar{V}_{\mathrm{ms}, x}$ & Sellers et al. (1996b) \\
\hline$T_{\mathrm{b}}$ & 281.15 & $\mathrm{~K}$ & minimum temperature for development & Bouman et al. (2001) \\
\hline$T_{\mathrm{h}}$ & 313.15 & $\mathrm{~K}$ & maximum temperature for development & Bouman et al. (2001) \\
\hline$T_{\mathrm{O}}$ & 303.15 & $\mathrm{~K}$ & optimal temperature for development & Bouman et al. (2001) \\
\hline$D_{\mathrm{vs}, \mathrm{tr}}$ & Parameterized & - & $D_{\mathrm{vs}}$ at transplanting and at which transplanting shock starts & Masutomi et al. (2016) \\
\hline$D_{\text {vs, te }}$ & Parameterized & - & $D_{\mathrm{vs}}$ at which transplanting shock ends & Masutomi et al. (2016) \\
\hline$t_{1}$ & 0.07 & - & leaf transmissivity for PAR & Sellers et al. (1996b) \\
\hline$t_{2}$ & 0.25 & - & leaf transmissivity for NIR & Sellers et al. (1996b) \\
\hline$V_{\max }(0)$ & Parameterized & $\mu \mathrm{mol} \mathrm{m}{ }^{-2} \mathrm{~s}^{-1}$ & maximum RuBisCO capacity at the canopy top & Masutomi et al. (2016) \\
\hline$z_{\mathrm{rt}, \mathrm{mx}}$ & 0.3 & $\mathrm{~m}$ & maximum root depth & Penning de Vries et al. (1989) \\
\hline$\beta_{\mathrm{ce}}$ & 0.98 & - & GPP transition factor & Sellers et al. (1996b) \\
\hline$\epsilon_{\mathrm{e}}$ & 0.08 & $\mathrm{~mol} \mathrm{~mol}^{-1}$ & quantum efficiency & Sellers et al. (1996b) \\
\hline \multicolumn{5}{|l|}{ Others } \\
\hline$A_{x, i}$ & C6-C7 & - & coefficients of radiation equations (Eqs. $12-14 ; x=1,2$ ) & Watanabe and Ohtani (1995) \\
\hline$a_{i}$ & $\mathrm{C} 1$ & - & extinction coefficient for scattered radiation & Watanabe and Ohtani (1995) \\
\hline$C_{0}$ & 288 & ppm & base concentration of $\mathrm{CO}_{2}$ for photosynthesis down-regulation & Arora et al. (2009) \\
\hline$c_{\mathrm{pm}}$ & 870 & $\mathrm{~J} \mathrm{~kg}^{-1} \mathrm{~K}^{-1}$ & specific heat of soil minerals & Campbell and Norman (1998) \\
\hline$D_{1}$ & $1.14 \times 10^{-11}$ & - & coefficient related to gravitational fall of canopy water & Rutter et al. (1975) \\
\hline$D_{2}$ & $3.7 \times 10^{3}$ & - & coefficient related to gravitational fall of canopy water & Rutter et al. (1975) \\
\hline$d_{\mathrm{f}}$ & $\sec (2 \pi(53 / 360))$ & - & scattered factor & Watanabe and Ohtani (1995) \\
\hline$F$ & 0.5 & - & distribution of leaf orientation & Goudriaan and van Laar (1994) \\
\hline$K_{\mathrm{n}}$ & 0.3 & - & vertical distribution of nitrogen & Oleson and Lawrence (2013) \\
\hline$k_{\mathrm{ts} 0}$ & 0.25 & $\mathrm{~W} \mathrm{~m}^{-1} \mathrm{~K}^{-1}$ & thermal conductivity of dry soil & Campbell and Norman (1998) \\
\hline$k_{\mathrm{tss}}$ & 1.58 & $\mathrm{~W} \mathrm{~m}^{-1} \mathrm{~K}^{-1}$ & thermal conductivity of saturated soil & Best et al. (2011) \\
\hline$\left[\mathrm{O}_{2}\right]$ & 20900 & $\mathrm{~Pa}$ & partial pressure of intercellular $\mathrm{O}_{2}$ & Collatz et al. (1991) \\
\hline$r_{\mathrm{g}}$ & 0.1 & - & albedo of surface for shortwave radiation & Maruyama and Kuwagata (2010) \\
\hline$s_{3}$ & 0.2 & $\mathrm{~K}^{-1}$ & temperature dependence of $\bar{V}_{\max , x}$ on $\bar{V}_{\mathrm{ms}, x}$ & Masutomi et al. (2016) \\
\hline$s_{5}$ & 1.3 & $\mathrm{~K}^{-1}$ & temperature dependence on $\bar{R}_{\mathrm{d}, x}$ & Sellers et al. (1996b) \\
\hline$s_{6}$ & 328 & $\mathrm{~K}$ & temperature dependence on $\bar{R}_{\mathrm{d}, x}$ & Sellers et al. (1996b) \\
\hline$z_{M \mathrm{~s}}$ & 0.001 & $\mathrm{~m}$ & roughness length of surface for momentum & Kimura and Kondo (1998) \\
\hline$z_{Q \mathrm{~s}}$ & 0.001 & $\mathrm{~m}$ & roughness length of surface for specific humidity & Kimura and Kondo (1998) \\
\hline$z_{T \mathrm{~s}}$ & 0.001 & $\mathrm{~m}$ & roughness length of surface for heat & Kimura and Kondo (1998) \\
\hline$\beta_{\mathrm{pc}}$ & 0.95 & - & GPP transition factor & Sellers et al. (1996b) \\
\hline$\epsilon$ & 0.96 & - & longwave emissivity of surface & Campbell and Norman (1998) \\
\hline$\gamma_{\mathrm{d}}$ & 0.9 & - & response parameter to elevated $\mathrm{CO}_{2}$ & Arora et al. (2009) \\
\hline$\gamma_{\mathrm{gd}}$ & 0.42 & - & response parameter to elevated $\mathrm{CO}_{2}$ & Arora et al. (2009) \\
\hline$\tau_{\mathrm{b}}$ & $8.64 \times 10^{6}$ & $\mathrm{~s}$ & recession constant for base water flow (100 days) & Hanasaki et al. (2008) \\
\hline
\end{tabular}

In addition, the following three assumptions are considered in the model for simplicity.

1. Leaf orientation is random (i.e. spherical distribution).

2. Leaf reflectivity and transmissivity of the radiation are vertically uniform within a canopy.

3. Scattered radiation is incoming from a zenith angle of $53^{\circ}$.

The first assumption may affect the accuracy of the model simulations. We know that leaf orientation of crops varies with their growth. However, there are no data on the change in leaf orientation for rice. Therefore, we assumed that the leaf orientation is random during the growing period. Assumption 3 is based on the fact that radiant flux uniformly emitted from a horizontal plane is approximately equal to radiant flux density from a zenith angle of $53^{\circ}$. From the three assumptions above, we can express analytically the radiant flux density for downward direct $\left(D_{i}^{\mathrm{d}}(l)\right)$, downward scattered $\left(S_{i}^{\mathrm{d}}(l)\right)$, and upward scattered $\left(S_{i}^{\mathrm{u}}(l)\right)$ within canopy for each waveband ( $i=1$ : PAR; $i=2$ : NIR) as follows:

$$
\begin{aligned}
D_{i}^{\mathrm{d}}(l) & =D_{i}^{\mathrm{d}}(0) \exp (-F l \sec (\theta)), \\
S_{i}^{\mathrm{d}}(l) & =C_{1, i} \exp \left(a_{i} l\right)+C_{2, i} \exp \left(-a_{i} l\right)+C_{3, i} D_{i}^{\mathrm{d}}(l),
\end{aligned}
$$




$$
\begin{aligned}
S_{i}^{\mathrm{u}}(l)= & A_{1, i} C_{1, i} \exp \left(a_{i} l\right)+A_{2, i} C_{2, i} \exp \left(-a_{i} l\right) \\
& +C_{4, i} D_{i}^{\mathrm{d}}(l) .
\end{aligned}
$$

Here, $F$ is a parameter for the distribution of leaf orientation. If we assume spherical distribution for leaf orientation as mentioned above, we have $F=0.5$ (Goudriaan and van Laar, 1994). The variable $l$ is a LAI depth from the canopy top. The variable $\theta$ is a zenith angle of the sun (Appendix B). The function sec indicates the secant function. The coefficients $a_{i}, C_{1, i}, C_{2, i}, C_{3, i}, C_{4, i}, A_{1, i}$, and $A_{2, i}$ are calculated as shown in Appendix $C$. It should be noted that $a_{i}$ indicates the extinction coefficient for scattered radiation. $D_{i}^{\mathrm{d}}(0)$ is obtained by splitting radiant flux density for downward shortwave at the top of the canopy into direct and scattered radiation as follows:

$D_{i}^{\mathrm{d}}(0)=0.5 R_{\mathrm{s}}^{\mathrm{d}}(0)\left(1-f_{\mathrm{df}}\right)$,

$S_{i}^{\mathrm{d}}(0)=0.5 R_{\mathrm{s}}^{\mathrm{d}}(0) f_{\mathrm{df}}$,

where $R_{\mathrm{S}}^{\mathrm{d}}(0)$ is the downward shortwave radiant flux density at the canopy top and $f_{\mathrm{df}}$ is the fraction of scattered radiation to total radiation. In Eqs. (15) and (16), we assumed that both PAR and NIR are half of $R_{\mathrm{s}}^{\mathrm{d}}(0)$. According to Goudriaan and van Laar (1994), $f_{\mathrm{df}}$ is given as a function of the transmissivity of atmosphere $\left(\tau_{\mathrm{atm}}\right)$ as follows:

$$
\begin{aligned}
f_{\mathrm{df}} & = \begin{cases}1 & \left(\tau_{\mathrm{atm}}<0.22\right) \\
1-6.4\left(\tau_{\mathrm{atm}}-0.22\right)^{2} & \left(0.22 \leq \tau_{\mathrm{atm}}<0.35\right) \\
1.47-1.66 \tau_{\mathrm{atm}} & (\text { otherwise })\end{cases} \\
\tau_{\mathrm{atm}} & =R_{\mathrm{s}}^{\mathrm{d}}(0) \sec (\theta) / R_{\mathrm{ex}}, \\
R_{\mathrm{ex}} & =R_{\mathrm{sun}}(1+0.033) \cos \left(2 \pi\left(D_{\mathrm{oy}} / 365\right)\right)
\end{aligned}
$$

where $R_{\text {ex }}$ is the extraterrestrial radiation, $R_{\text {sun }}$ is the solar constant, and $D_{\text {oy }}$ is the number of days from 1 January. The Eqs. (15)-(19) that calculate $D_{i}^{\mathrm{d}}(0)$ are based on formulations by Goudriaan and van Laar (1994), while the original MATSIRO uses different equations.

The transmissivity of canopies for shortwave radiation $\left(\tau_{\mathrm{cs}}\right)$ is expressed as

$$
\tau_{\mathrm{cs}}=R_{\mathrm{s}}^{\mathrm{d}}(L) /\left(R_{\mathrm{s}}^{\mathrm{d}}(0)-R_{\mathrm{s}}^{\mathrm{u}}(0)\right)
$$

Here, $R_{\mathrm{s}}^{\mathrm{u}}(0)$ and $R_{\mathrm{s}}^{\mathrm{d}}(L)$ are the radiant flux density for upward shortwave at the canopy top and downward shortwave at the bottom of the canopy, respectively. $L$ denotes the LAI, which is calculated in the CGM (Sect. 4.4). $R_{\mathrm{S}}^{\mathrm{u}}(0)$ and $R_{\mathrm{S}}^{\mathrm{d}}(L)$ are represented by

$R_{\mathrm{s}}^{\mathrm{u}}(0)=r_{11} D_{1}^{\mathrm{d}}(0)+r_{21} D_{2}^{\mathrm{d}}(0)+r_{12} S_{1}^{\mathrm{d}}(0)+r_{22} S_{2}^{\mathrm{d}}(0)$,

$R_{\mathrm{s}}^{\mathrm{d}}(L)=\tau_{11} D_{1}^{\mathrm{d}}(0)+\tau_{21} D_{2}^{\mathrm{d}}(0)+\tau_{12} S_{1}^{\mathrm{d}}(0)+\tau_{22} S_{2}^{\mathrm{d}}(0)$,

where $r_{i j}$ and $\tau_{i j}$ are the canopy reflectivity and transmissivity, respectively, and $i$ and $j$ represent wavebands $(i=1$ :
PAR; $i=2$ : NIR) and direct $(j=1)$ or scattered radiation $(j=2)$. These are given in Appendix D.

Last, the transmissivity of a canopy for longwave radiation $\left(\tau_{\mathrm{cl}}\right)$ is expressed as

$\tau_{\mathrm{cl}}=\exp \left(-F L d_{\mathrm{f}}\right)$,

where $d_{\mathrm{f}}$ is the scattered factor. We set $d_{\mathrm{f}}=\sec (2 \pi(53 / 360))$ from assumption 3 described above.

\subsection{Bulk transfer coefficient for latent and sensible heat}

This module calculates BTCs for latent and sensible heat $\left(C_{E_{\mathrm{c}}}, C_{E_{\mathrm{g}}}, C_{H_{\mathrm{c}}}\right.$, and $\left.C_{H_{\mathrm{g}}}\right)$. The BTCs are used to simulate energy balance (Sect. 3.1). This module is based on Watanabe (1994), where $C_{E_{\mathrm{g}}}, C_{E_{\mathrm{c}}}, C_{H_{\mathrm{g}}}$, and $C_{H_{\mathrm{c}}}$ are given by

$$
\begin{aligned}
C_{E_{\mathrm{g}}}= & {\left[1 / C_{H_{\mathrm{g}}}+r_{\mathrm{s}} U\right]^{-1}, } \\
C_{E_{\mathrm{c}}}= & C_{E}-C_{E_{\mathrm{g}}}, \\
C_{H_{\mathrm{g}}}= & \kappa^{2}\left[\ln \left(\frac{z_{\mathrm{a}}-d}{z_{M \mathrm{~g}}}\right)+\Psi_{M}\left(\zeta_{\mathrm{g}}\right)\right]^{-1}\left[\ln \left(\frac{z_{\mathrm{a}}-d}{z_{T \mathrm{~g}}}\right)\right. \\
& \left.+\Psi_{H}\left(\zeta_{\mathrm{g}}\right)\right]^{-1}, \\
C_{H_{\mathrm{c}}}= & C_{H}-C_{H_{\mathrm{g}}},
\end{aligned}
$$

where $C_{E}$ and $C_{H}$ are the BTCs for latent and sensible heat between the entire surface (canopy plus surface) and atmosphere, and are given by

$$
\begin{aligned}
C_{E}= & \kappa^{2}\left[\ln \left(\frac{z_{\mathrm{a}}-d}{z_{M}}\right)+\Psi_{M}(\zeta)\right]^{-1}\left[\ln \left(\frac{z_{\mathrm{a}}-d}{z_{Q}}\right)\right. \\
& \left.+\Psi_{E}(\zeta)\right]^{-1}, \\
C_{H}= & \kappa^{2}\left[\ln \left(\frac{z_{\mathrm{a}}-d}{z_{M}}\right)+\Psi_{M}(\zeta)\right]^{-1}\left[\ln \left(\frac{z_{\mathrm{a}}-d}{z_{T}}\right)\right. \\
& \left.+\Psi_{H}(\zeta)\right]^{-1} .
\end{aligned}
$$

In Eqs. (24)-(29), $\kappa$ is the Karman constant; $d$ is the zeroplane displacement height; $z_{\mathrm{a}}$ is the reference height at which wind velocity is observed; $z_{M \mathrm{~g}}$ and $z_{T \mathrm{~g}}$ are the roughness lengths that express the effect of surface on the profiles of momentum and temperature, respectively; $z_{M}, z_{T}$, and $z_{Q}$ are the roughness lengths of an entire surface (canopy plus surface) for the profiles of momentum, temperature, and specific humidity, respectively; and $r_{\mathrm{s}}$ is resistance of topsoil to evaporation. $z_{\mathrm{a}}$ is a simulation setting parameter (Table 6), and $d, z_{M}, z_{T}, z_{Q}, z_{M \mathrm{~g}}$ and $z_{T \mathrm{~g}}$ are the functions of crop height and LAI (Appendix E). $r_{\mathrm{s}}$ is given by

$r_{\mathrm{s}}=800\left(1-w_{\mathrm{s}}(0) / w_{\mathrm{sat}}\right) /\left(0.2+w_{\mathrm{s}}(0) / w_{\text {sat }}\right)$,

where $w_{\mathrm{S}}(0)$ is the water content of topsoil and is calculated in Eq. (53), and $w_{\text {sat }}$ is the soil water content at saturation and is a soil-type specific parameter. $\Psi_{M}, \Psi_{H}$, and 
$\Psi_{E}$ are the diabatic correction factors for momentum, heat, and vapour transport, respectively. The factors are functions of atmospheric stability $\zeta$ as follows:

$\Psi_{M}(\zeta)=\left\{\begin{array}{c}6 \ln (1+\zeta) \\ (\zeta>0: \text { stable }) \\ -1.2 \ln \left[\frac{1+(1-16 \zeta)^{1 / 2}}{2}\right] \\ \quad \text { otherwise: unstable) }\end{array}\right.$

$\Psi_{H}(\zeta)=\Psi_{E}(\zeta)=\left\{\begin{array}{c}6 \ln (1+\zeta) \\ (\zeta>0: \text { stable }) \\ -2 \ln \left[\frac{1+(1-16 \zeta)^{1 / 2}}{2}\right] \\ (\text { otherwise: stable) } .\end{array}\right.$

The equations above are adopted from Campbell and Norman (1998), whereas the original MATSIRO model employs different equations. The variable $\zeta$ is replaced by either the atmospheric stability between the entire surface and atmosphere $(\zeta)$ or the atmospheric stability between surface and atmosphere $\left(\zeta_{\mathrm{g}}\right)$. These are given by

$\zeta=\frac{z_{\mathrm{a}}-d}{L_{\mathrm{MO}}}$

$\zeta_{\mathrm{g}}=\frac{z_{\mathrm{a}}-d}{L_{\mathrm{MOg}}}$,

where $L_{\mathrm{MO}}$ and $L_{\mathrm{MOg}}$ are the Monin-Obukhov lengths for the exchange between the entire surface and atmosphere and between the surface and atmosphere, respectively, and are given by

$$
\begin{aligned}
L_{\mathrm{MO}} & =\frac{\Theta_{0} C_{M}^{3 / 2} U^{2}}{\kappa g\left\{C_{H_{\mathrm{g}}}\left(T_{\mathrm{g}}-T_{\mathrm{a}}\right)+C_{H_{\mathrm{c}}}\left(T_{\mathrm{c}}-T_{\mathrm{a}}\right)\right\}}, \\
L_{\mathrm{MOg}} & =\frac{\Theta_{0} C_{M \mathrm{~g}}^{3 / 2} U^{2}}{\kappa g C_{H_{\mathrm{g}}}\left(T_{\mathrm{g}}-T_{\mathrm{a}}\right)},
\end{aligned}
$$

where $g$ is the gravitational constant, $T_{\mathrm{g}}$ and $T_{\mathrm{c}}$ are the temperatures of the surface and canopy, $\Theta_{0}$ is the potential temperature, $C_{M}$ and $C_{M \mathrm{~g}}$ are the BTC for momentum between an entire surface and atmosphere and between surface and atmosphere, respectively. $C_{M \mathrm{~g}}$ in Eq. (36) is introduced according to Maruyama and Kuwagata (2008), while the original MATSIRO uses $C_{M} . T_{\mathrm{g}}$ and $T_{\mathrm{c}}$ are calculated in Sect. 3.1. $\Theta_{0}$ is given by

$\Theta_{0}=T_{\mathrm{a}} \times\left(1.0 \times 10^{5} / P_{\mathrm{a}}\right)^{\left(R_{\mathrm{dry}} / c_{\mathrm{pa}}\right)}$,

where $R_{\text {dry }}$ is the gas constant of dry air. Although the original MATSIRO fixes $\Theta_{0}$ at $300 \mathrm{~K}$, MATCRO calculates the value according to Campbell and Norman (1998). $C_{M}$ and $C_{M \mathrm{~g}}$ are given by

$C_{M}=k^{2}\left[\ln \left(\frac{z_{\mathrm{a}}-d}{z_{M}}\right)+\Psi_{M}(\zeta)\right]^{-2}$,
$C_{M \mathrm{~g}}=k^{2}\left[\ln \left(\frac{z_{\mathrm{a}}-d}{z_{M \mathrm{~g}}}\right)+\Psi_{M}\left(\zeta_{\mathrm{g}}\right)\right]^{-2}$.

Now we have six independent equations, Eqs. (24), (25), (26), (27), (38), and (39), for six unknown variables, $C_{E_{\mathrm{g}}}$, $C_{E_{\mathrm{c}}}, C_{H_{\mathrm{g}}}, C_{H_{\mathrm{c}}}, C_{M}$, and $C_{M \mathrm{~g}}$, respectively. Therefore, we can determine the values of these variables by numerically solving Eqs. (24)-(39). The numerical method is described in Masutomi et al. (2016).

\subsection{Canopy water balance}

The main purpose of this module is to calculate the fraction of wet canopy $\left(f_{\mathrm{cw}}\right)$ which is used for simulating energy balance at canopy (Sect. 3.1). To calculate $f_{\mathrm{cw}}$, this module calculates water balance at canopy. Although the module is based on the original MATSIRO, the amount of water that canopies can hold was replaced by using the method described in Penning de Vries et al. (1989). The variable $f_{\mathrm{cw}}$ is given as

$f_{\mathrm{cw}}=w_{\mathrm{c}} / w_{\mathrm{cap}}$,

where $w_{\mathrm{c}}$ is the amount of water stored in canopy and $w_{\text {cap }}$ is the water capacity of the canopy. The $w_{\mathrm{c}}$ is calculated by solving the canopy water balance, which is given by

$\rho_{\mathrm{w}} \frac{\mathrm{d} w_{\mathrm{c}}}{\mathrm{d} t}=I_{\mathrm{c}}-D_{\mathrm{g}}-E_{\mathrm{c}}$,

where $\rho_{\mathrm{w}}$ is the density of water, $I_{\mathrm{c}}$ is the amount of precipitation intercepted by canopy, $D_{\mathrm{g}}$ is the amount of water that falls from the canopy onto surface due to gravity, and $E_{\mathrm{c}}$ is the amount of water that evaporates from the canopy (Eq. 7). $I_{\mathrm{c}}$ depends on the amount of precipitation $\left(P_{\mathrm{r}}\right)$ and LAI $(L)$ and is given by

$I_{\mathrm{c}}=f_{\text {int }} P_{\mathrm{r}}$,

$f_{\text {int }}= \begin{cases}L & (L<1), \\ 1 & (\text { otherwise }),\end{cases}$

where $f_{\text {int }}$ indicates the interception efficiency of precipitation by canopy. According to Rutter et al. (1975) and Penning de Vries et al. (1989), $D_{\mathrm{g}}$ and $w_{\text {cap }}$ are given as

$D_{\mathrm{g}}=\rho_{\mathrm{w}} D_{1} \exp \left(D_{2} w_{\mathrm{c}}\right)$,

$w_{\text {cap }}=\left(W_{\text {sh }} \times 10^{-4}\right) / \rho_{\mathrm{w}}$,

respectively, where $D_{1}$ and $D_{2}$ are parameters (Rutter et al., 1975), and $W_{\text {sh }}$ is the shoot dry weight, which is calculated in the CGM (Eq. 136). In the case of non-flooded surface, the amount of water that falls from the canopy onto soil surface, $F_{\mathrm{c}}$, is calculated by

$F_{\mathrm{c}}=D_{\mathrm{g}}+\left(1-f_{\text {int }}\right) P_{\mathrm{r}}+\max \left\{0, w_{\mathrm{c}}-w_{\text {cap }}\right\} \rho_{\mathrm{w}} / \delta t$, 
where $\delta t$ is the time resolution of simulations. In the case of flooded surface, $F_{\mathrm{c}}$ is not calculated because surface water is present. The maximum evaporation from the canopy $\left(E_{\mathrm{c}, \max }\right)$ is given by

$E_{\mathrm{c}, \max }=w_{\mathrm{c}} \rho_{\mathrm{w}} / \delta t$.

\subsection{Soil water and heat transfer}

This module calculates heat and water transfer in soil. The main role of this module is to determine the temperature at a soil surface $\left(T_{\mathrm{S}}(0)\right)$, which is used for simulating energy balance of the surface (Sect. 3.1). Although this module is based on the original MATSIRO, the calculations of the surface and base runoffs are simplified because hydrological calculations are not the main purpose of MATCRO-Rice.

Soil temperature at a soil depth of $z$ from the soil surface $\left(T_{\mathrm{S}}(z)\right)$ is calculated from the gradient of heat flux in the soil as follows:

$c_{\mathrm{hs}}(z) \frac{\partial T_{\mathrm{s}}(z)}{\partial t}=\frac{\partial G_{\mathrm{s}}(z)}{\partial z}$,

where $c_{\mathrm{hs}}$ is the volumetric heat capacity of the soil and $G_{\mathrm{S}}(z)$ is the heat flux at a soil depth of $z$ and is given from the gradient of soil temperature as

$G_{\mathrm{s}}(z)= \begin{cases}k_{\mathrm{ts}}(z) \frac{\partial T_{\mathrm{s}}(z)}{\partial z} & \left(0 \leq z<z_{\max }\right) \\ 0 & \left(z=z_{\max }\right) .\end{cases}$

Here, $k_{\mathrm{ts}}$ is the soil thermal conductivity. In Eq. (49), we assumed that heat flux at the bottom of the soil layer $\left(z=z_{\max }\right)$ is zero. $z_{\max }$ is a simulation setting parameter. When solving Eqs. (48) and (49), the heat flux from surface to soil $\left(G_{\mathrm{gs}}\right)$, calculated in Eq. (10), is used as a boundary condition. The parameter $c_{\mathrm{hs}}$ is calculated from the heat capacities of soil components as follows:

$c_{\mathrm{hs}}(z)=\rho_{\mathrm{s}} c_{\mathrm{pm}}+\rho_{\mathrm{w}} c_{\mathrm{pw}} w_{\mathrm{s}}(z)$

where $\rho_{\mathrm{s}}$ is the bulk density of soil, $c_{\mathrm{pm}}$ is the specific heat of soil minerals, and $w_{\mathrm{s}}(z)$ is the volumetric concentration of soil water. $\rho_{\mathrm{s}}$ is a soil-type specific parameter determined by soil type at a simulation site, and $c_{\mathrm{pm}}$ is given according to Campbell and Norman (1998). We note that the first term of the right hand side in Eq. (50) indicates the heat capacity of dry soil. Although the original MATSIRO model assigns a default value to the heat capacity of dry soil for all soil types, MATCRO-Rice calculates the value of the heat capacity of dry soil using the bulk density of soil and the heat capacity of soil minerals, as shown in the first term of Eq. (50). It should be noted that the effect of soil organic matter on $c_{\mathrm{hs}}$ is not considered in MATCRO. The parameter $k_{\mathrm{ts}}(z)$ in Eq. (49) is given by

$$
\begin{aligned}
& k_{\mathrm{ts}}(z)=K_{\mathrm{e}}(z)\left(k_{\mathrm{tss}}-k_{\mathrm{ts} 0}\right)+k_{\mathrm{ts} 0} \\
& K_{\mathrm{e}}(z)= \begin{cases}\log \left(w_{\mathrm{s}}(z) / w_{\mathrm{sat}}\right)+1.0 & \left(\text { if } w_{\mathrm{s}}(z) / w_{\mathrm{sat}} \geq 0\right), \\
0 & (\text { otherwise })\end{cases}
\end{aligned}
$$

where $k_{\mathrm{ts} 0}$ and $k_{\mathrm{tss}}$ are the thermal conductivity of dry and saturated soils, respectively, $K_{\mathrm{e}}$ is the Kersten number, and $w_{\text {sat }}$ is the volumetric soil water concentration at saturation. $k_{\mathrm{ts} 0}$ and $k_{\mathrm{tss}}$ are parameters. We set $k_{\mathrm{ts} 0}=0.25$ (Campbell and Norman, 1998) and $k_{\mathrm{tss}}=1.58$ (Best et al., 2011). The parameter $w_{\text {sat }}$ is specific to soil type. Equations (51) and (52) for the calculation of $k_{\text {ts }}(z)$ are based on the equations developed by Best et al. (2011), while the original MATSIRO employs a different equation. The variable $w_{\mathrm{s}}(z)$ depends on the gradient of water flux and absorption by roots at a soil depth $z$. In addition, water flux from the canopy layer is added into the top layer of the soil $\left(0 \leq z<z_{\mathrm{t}}\right)$ in the case of non-flooded surface. The variable $w_{\mathrm{s}}(z)$ is given by

$$
\frac{\partial w_{\mathrm{s}}(z)}{\partial t}= \begin{cases}\frac{\partial F_{\mathrm{s}}(z)}{\partial z}-S_{\mathrm{S}}(z)+F_{\mathrm{c}} & \left(0 \leq z<z_{\mathrm{t}}\right), \\ \frac{\partial F_{\mathrm{s}}(z)}{\partial z}-S_{\mathrm{S}}(z) & \left(z_{\mathrm{t}}<z \leq z_{\mathrm{b}}\right),\end{cases}
$$

where $F_{\mathrm{S}}(z)$ and $S_{\mathrm{S}}(z)$ are water flux and absorption by roots at a soil depth of $z$, respectively. $F_{\mathrm{c}}$ is water flux from the canopy layer (Eq. 46). In the case of flooded surface, the topsoil layer is assumed to be saturated as follows:

$w_{\mathrm{s}}(z)=w_{\text {sat }}$ (if flooded; $\left.0 \leq z<z_{\mathrm{t}}\right)$.

This assumption is not considered in the original MATSIRO. $z_{\mathrm{t}}$ is a simulation setting parameter. $F_{\mathrm{S}}(z)$ is calculated from the gradient of water potentials as follows:

$F_{\mathrm{s}}(z)= \begin{cases}-K(z)\left(\frac{\partial \psi(z)}{\partial z}+1\right) & \left(0 \leq z \leq z_{\mathrm{b}}\right) \\ \left(w_{\mathrm{sat}} / \tau_{\mathrm{b}}\right)\left(w_{\mathrm{s}}(z) / w_{\mathrm{sat}}\right)^{2} & \left(z_{\mathrm{b}}<z \leq z_{\max }\right)\end{cases}$

where $K(z)$ is the hydraulic conductivity and $\psi(z)$ is the water potential at a soil depth of $z . F_{\mathrm{S}}(z)$ in the bottommost layer $\left(z_{\mathrm{b}}<z<z_{\max }\right)$ represents the base flow, and $\tau_{\mathrm{b}}$ is the recession constant for base flow. This model uses a simple model for simulating base flow developed by Hanasaki et al. (2008), although the original MATSIRO utilizes a more complicated model (TOPMODEL: Beven and Kirkby, 1979). $z_{\mathrm{b}}$ is a simulation setting parameter, and $\tau_{\mathrm{b}}$ is determined as described in Hanasaki et al. (2008). $K(z)$ and $\psi(z)$ are given by Clapp and Hornberger (1978) as follows:

$$
\begin{aligned}
& K(z)=K_{\mathrm{s}}\left(\frac{w_{\mathrm{s}}(z)}{w_{\mathrm{sat}}}\right)^{2 B+3}, \\
& \psi(z)=\psi_{\mathrm{s}}\left(\frac{w_{\mathrm{s}}(z)}{w_{\mathrm{sat}}}\right)^{-B},
\end{aligned}
$$

where $K_{\mathrm{S}}$ and $\psi_{\mathrm{s}}$ are hydraulic conductivity and water potentials at saturation, respectively, and $B$ is a parameter that determines the relationship of hydraulic conductivity or water potentials between saturated and unsaturated soils. $K_{\mathrm{s}}$, $\psi_{\mathrm{s}}$, and $B$ are soil-type specific parameters. $S_{\mathrm{S}}(z)$ in Eq. (53) is calculated from the transpiration

$$
S_{\mathrm{S}}(z)= \begin{cases}\left(E_{\mathrm{t}} / \rho_{\mathrm{W}}\right) f_{\mathrm{r}}(z) & \left(0 \leq z \leq z_{\mathrm{rt}}\right), \\ 0 & \left(z_{\mathrm{rt}}<z \leq z_{\max }\right)\end{cases}
$$


where $E_{\mathrm{t}}$ is the transpiration calculated in Eq. (8), $z_{\mathrm{rt}}$ is a root depth calculated by the CGM (Eq. 140), $f_{\mathrm{r}}(z)$ is the distribution of the root and is given by

$$
f_{\mathrm{r}}(z)=(3 / 2)\left(z_{\mathrm{rt}}^{2}-z^{2}\right) / z_{\mathrm{rt}}^{3},
$$

where we assumed that the root has no spatial orientation and is equally distributed in soil. We note that the root depth and distribution in MATCRO changes, although those variables are fixed in the original MATSIRO. The humidity of topsoil, $h_{\mathrm{ms}}$, used in Eq. (9) is given by

$h_{\mathrm{ms}}=\exp \left(\psi(0) g /\left(R_{\mathrm{a}} T_{\mathrm{s}}(0)\right)\right.$.

In MATCRO, it is assumed that crops can use soil water beyond the wilting point with water potential of $-1500 \mathrm{kPa}$ $\left(w_{\mathrm{wlt}}\right)$. Hence, the maximum transpiration $\left(E_{\mathrm{t}, \max }\right)$ is given by

$E_{\mathrm{t}, \max }=\frac{\rho_{\mathrm{w}}}{\delta t} \int_{0}^{z_{\mathrm{rt}}}\left(w_{\mathrm{s}}(z)-w_{\mathrm{wlt}}\right) \mathrm{d} z$,

where $w_{\text {wlt }}$ is a soil-type specific parameter, and $\delta t$ is the time resolution of simulations. In the case of non-flooded surface, evaporation from the surface $\left(E_{\mathrm{g}}\right)$ is limited by soil water in the topsoil layer $\left(0 \leq z<z_{\mathrm{t}}\right)$ and is given by

$E_{\mathrm{g}, \max }=\frac{\rho_{\mathrm{w}}}{\delta t} \int_{0}^{z_{\mathrm{t}}}\left(w_{\mathrm{s}}(z)\right) \mathrm{d} z$.

In the case of flooded surface, there is no limitation for $E_{\mathrm{g}, \text { max }}$.

\section{Crop growth model}

The main purpose of the CGM is to simulate rice yield and biomass growth for each organ during a growing period. The CGM has four modules: net carbon assimilation, crop development, crop growth, and LAI, crop height, and root depth. Each module is described in detail in the following sections.

\subsection{Net carbon assimilation}

The main role of this module is to calculate net carbon assimilation $\left(A_{\mathrm{n}}\right)$ in canopy for simulating crop growth. In addition, the stomatal conductance per unit leaf area for both sides of the leave $\left(\bar{g}_{\mathrm{s}}\right)$ is calculated for simulating roughness length (Appendix E). Although this module is based on the big-leaf model (Sellers et al., 1992, 1996a) used in the original MATSIRO, we refined two points in the calculation according to the approach described by de Pury and Farquhar (1997) and Dai et al. (2004). The first refinement is that leaves in a canopy are divided into sunlit and shade leaves. Subsequently, $A_{\mathrm{n}}$ per unit leaf area for each the sunlit and shade leaves are calculated. The second refinement is that $A_{\mathrm{n}}$ for the entire canopy is calculated considering vertical distribution of nitrogen within the canopy.

$A_{\mathrm{n}}$ for the entire canopy is given by

$A_{\mathrm{n}}=\bar{A}_{\mathrm{n}, \mathrm{sn}} L_{\mathrm{sn}}+\bar{A}_{\mathrm{n}, \mathrm{sh}} L_{\mathrm{sh}}$,

where $\bar{A}_{\mathrm{n}, \mathrm{sn}}$ and $\bar{A}_{\mathrm{n}, \mathrm{sh}}$ are net carbon assimilation per unit leaf area for sunlit and shade leaves, respectively, $L_{\mathrm{sn}}$ and $L_{\mathrm{sh}}$ are LAI for sunlit and shade leaves, respectively, and overbars represent the amounts per unit leaf area. $\bar{A}_{\mathrm{n}, \mathrm{sn}}$ and $\bar{A}_{\mathrm{n}, \mathrm{sh}}$ are defined by the difference between gross carbon assimilation and respiration as follows:

$\bar{A}_{\mathrm{n}, x}=\bar{A}_{\mathrm{g}, x}-\bar{R}_{\mathrm{d}, x}$,

where $\bar{A}_{\mathrm{g}, x}$ and $\bar{R}_{\mathrm{d}, x}$ are gross carbon assimilation and respiration per unit leaf area, respectively, and the suffix $x$ indicates sn or sh. $L_{\mathrm{sn}}$ and $L_{\mathrm{sh}}$ are given as follows:

$L_{\mathrm{sn}}=\int_{0}^{L} f_{\mathrm{sn}}(l) \mathrm{d} l$,

$L_{\mathrm{sh}}=\int_{0}^{L}\left(1-f_{\mathrm{sn}}(l)\right) \mathrm{d} l$,

where $f_{\mathrm{sn}}(l)$ is the fraction of sunlit leaves at a LAI depth of $l$ and is defined as follows:

$f_{\mathrm{sn}}(l)=\exp (-F l \sec (\theta))$,

where $F$ denotes distribution of leaf orientation and $\theta$ is a zenith angle of the sun (Appendix B). The effect of photosynthesis down-regulation due to acclimatization to elevated $\mathrm{CO}_{2}$ is represented as follows:

$\bar{A}_{\mathrm{g}, x}=f_{\mathrm{dwn}} \bar{A}_{\mathrm{g}^{\prime}, x}$,

$f_{\mathrm{dwn}}=\left\{1+\gamma_{\mathrm{gd}} \ln \left(C_{\mathrm{a}, \mathrm{ppm}} / C_{0}\right)\right\} /\left\{1+\gamma_{\mathrm{g}} \ln \left(C_{\mathrm{a}, \mathrm{ppm}} / C_{0}\right)\right\}$,

where $\bar{A}_{\mathrm{g}^{\prime}, x}$ is gross carbon assimilation per unit leaf area for sunlit and shade leaves without photosynthesis downregulation, $f_{\mathrm{dwn}}$ is the factor for photosynthesis downregulation, $\gamma_{\mathrm{gd}}$ and $\gamma_{\mathrm{g}}$ are parameters that characterize the response to increased $\mathrm{CO}_{2}, C_{\mathrm{a} \text {,ppm }}$ is atmospheric $\mathrm{CO}_{2}$ concentration, and $C_{0}$ is the base concentration of $\mathrm{CO}_{2}$. The Eqs. (68) and (69) are based on Arora et al. (2009), although the original MATSIRO does not consider the effect of photosynthesis down-regulation. We set $\gamma_{\mathrm{gd}}=0.42, \gamma_{\mathrm{g}}=0.9$, and $C_{0}=288$ according to Arora et al. (2009). It should be noted that we have tentatively set these values for the parameters of photosynthesis down-regulation, using the mean values in Arora et al. (2009), because these values are not available for rice. If these values are quantified, they should be replaced. The calculation for $\bar{A}_{\mathrm{g}^{\prime}, x}$ and $\bar{R}_{\mathrm{d}, x}$ is based on the leaf photosynthesis model developed by Collatz et al. (1991). 
In their model, $\bar{A}_{\mathrm{g}^{\prime}, x}$ is determined by three limiting factors: RuBisCO, light, and sucrose synthesis as follows:

$\bar{A}_{\mathrm{g}^{\prime}, x} \leq \min \left(\bar{\omega}_{\mathrm{c}, x}, \bar{\omega}_{\mathrm{e}, x}, \bar{\omega}_{\mathrm{s}, x}\right)$,

where $\bar{\omega}_{\mathrm{c}, x}, \bar{\omega}_{\mathrm{e}, x}$, and $\bar{\omega}_{\mathrm{s}, x}$ are RuBisCO-limited, lightlimited, and sucrose-limited carbon assimilation per unit leaf area, respectively. To implement smooth transition between each limited state, $\bar{A}_{\mathrm{g}^{\prime}, x}$ is determined practically by solving the following two equations (Sellers et al., 1996b):

$\beta_{\mathrm{ce}} \bar{\omega}_{\mathrm{p}, x}^{2}-\bar{\omega}_{\mathrm{p}, x}^{2}\left(\bar{\omega}_{\mathrm{c}, x}^{2}+\bar{\omega}_{\mathrm{e}, x}^{2}\right)+\bar{\omega}_{\mathrm{c}, x}^{2} \bar{\omega}_{\mathrm{e}, x}^{2}=0$

$\beta_{\mathrm{ps}} \bar{A}_{\mathrm{g}^{\prime}, x}^{2}-\bar{A}_{\mathrm{g}^{\prime}, x}^{2}\left(\bar{\omega}_{\mathrm{p}, x}^{2}+\bar{\omega}_{\mathrm{s}, x}^{2}\right)+\bar{\omega}_{\mathrm{p}, x}^{2} \bar{\omega}_{\mathrm{s}, x}^{2}=0$,

where $\beta_{\mathrm{ce}}$ and $\beta_{\mathrm{pc}}$ are the parameters that determine the smoothness of transition between each limited state. $\beta_{\text {ce }}$ is a crop-specific parameter and $\beta_{\mathrm{pc}}$ is a parameter that does not depend on crop type. The variables $\bar{\omega}_{\mathrm{c}, x}, \bar{\omega}_{\mathrm{e}, x}$, and $\bar{\omega}_{\mathrm{s}, x}$ are given by

$\bar{\omega}_{\mathrm{c}, x}=\bar{V}_{\mathrm{mc}, x}\left\{\frac{c_{\mathrm{i}, x}-\Gamma^{*}}{c_{\mathrm{i}, x}+K_{\mathrm{c}}\left(1+\left[\mathrm{O}_{2}\right] / K_{\mathrm{O}}\right)}\right\}$

$\bar{\omega}_{\mathrm{e}, x}=\epsilon_{\mathrm{e}} \bar{Q}_{x}\left\{\frac{c_{\mathrm{i}, x}+\Gamma^{*}}{c_{\mathrm{i}, x}+2 \Gamma^{*}}\right\}$

$\bar{\omega}_{\mathrm{s}, x}=\bar{V}_{\mathrm{ms}, x} / 2$.

Here, $\bar{V}_{\mathrm{mc}, x}$ and $\bar{V}_{\mathrm{ms}, x}$ are the maximum RuBisCO capacity per unit leaf area for $\bar{\omega}_{\mathrm{c}, x}$ and $\bar{\omega}_{\mathrm{s}, x}$, respectively, $c_{\mathrm{i}, x}$ is the partial pressure of intercellular $\mathrm{CO}_{2},\left[\mathrm{O}_{2}\right]$ is the partial pressure of intercellular $\mathrm{O}_{2}, \bar{Q}_{x}$ is the photon flux density for PAR absorbed per unit leaf area by sunlit and shade leaves, $\epsilon_{\mathrm{e}}$ is the quantum efficiency, $\Gamma^{*}$ is the light compensation point, and $K_{\mathrm{c}}$ and $K_{\mathrm{O}}$ are the Michaelis constant for $\mathrm{CO}_{2}$ fixation and oxygen inhibition, respectively. We set $\left[\mathrm{O}_{2}\right]=20900$ (Collatz et al., 1991). $\epsilon_{\mathrm{e}}$ is a crop-specific parameter. $\bar{V}_{\mathrm{mc}, x}$ and $\bar{V}_{\mathrm{ms}, x}$ are given by

$\bar{V}_{\mathrm{mc}, x}=\bar{V}_{\max , x} f_{\mathrm{v}}\left[2^{q_{\mathrm{t}}} /\left\{1+\exp \left(s_{1}\left(T_{\mathrm{c}}-s_{2}\right)\right)\right\}\right]$,

$\bar{V}_{\mathrm{ms}, x}=\bar{V}_{\max , x} f_{\mathrm{v}}\left[2^{q_{\mathrm{t}}} /\left\{1+\exp \left(s_{3}\left(s_{4}-T_{\mathrm{c}}\right)\right)\right\}\right]$,

where $\bar{V}_{\max , x}$ is the reference value for the maximum $\mathrm{Ru}-$ BisCO capacity per unit leaf area of sunlit $\left(\bar{V}_{\max , \mathrm{sn}}\right)$ and shade $\left(\bar{V}_{\max , \mathrm{sh}}\right)$ leaves; $f_{\mathrm{v}}$ is the water stress factor; $s_{1}, s_{2}$, $s_{3}$, and $s_{4}$ are parameters that represent temperature dependence of $\bar{V}_{\max , x}$ on $\bar{V}_{\mathrm{mc}, x}$ or $\bar{V}_{\mathrm{ms}, x}$; and $q_{\mathrm{t}}$ is a function that represents temperature dependency. The variables $s_{1}$ and $s_{2}$ are parameterized in Masutomi et al. (2016), whereas $s_{3}$ is a parameter that does not depend on crop type and $s_{4}$ is a crop-specific parameter. $f_{\mathrm{v}}$ is given by

$$
\begin{aligned}
& f_{\mathrm{v}}=\int_{0}^{r_{\mathrm{t}}} f_{\mathrm{r}}(z) f_{\mathrm{s}}(z) \mathrm{d} z, \\
& f_{\mathrm{s}}(z)=\frac{2}{1+\exp \left(-\gamma_{\mathrm{s}} \psi_{\mathrm{s}}(z)\right)},
\end{aligned}
$$

where $f(z)$ is the water stress function on photosynthesis at a soil depth of $z$, and $\gamma_{\mathrm{s}}$ is a crop-specific parameter for water stress on photosynthesis. Equation (79) is based on Bouman et al. (2001), although the original MATSIRO uses a different equation. $q_{\mathrm{t}}$ is given by

$q_{\mathrm{t}}=\left(T_{\mathrm{c}}-298\right) / 10$.

$\bar{V}_{\max , \text { sn }}$ and $\bar{V}_{\max , \mathrm{sh}}$ are defined by

$\bar{V}_{\max , \mathrm{sn}}=\left(\int_{0}^{L} V_{\max }(l) f_{\mathrm{sn}}(l) \mathrm{d} l\right) / L_{\mathrm{sn}}$,

$\bar{V}_{\max , \mathrm{sh}}=\left(\int_{0}^{L} V_{\max }(l)\left(1-f_{\mathrm{sn}}(l)\right) \mathrm{d} l\right) / L_{\mathrm{sh}}$,

where $V_{\max }(l)$ is the reference value for the maximum $\mathrm{Ru}$ BisCO capacity at a LAI depth of $l$. The vertical distribution of $V_{\max }(l)$ depends on that of leaf nitrogen within the canopy and is given by

$V_{\max }(l)=V_{\max }(0) \exp \left(-K_{\mathrm{n}} l\right)$,

where $K_{\mathrm{n}}$ is a parameter that represents the vertical distribution of leaf nitrogen, and $V_{\max }(0)$ is the reference value for the maximum RuBisCO capacity at the canopy top. $V_{\max }(0)$ as well as $s_{1}$ and $s_{2}$ are parameterized in Masutomi et al. (2016), and we set $K_{\mathrm{n}}=0.3$ (Oleson and Lawrence, 2013). $\Gamma^{*}, K_{\mathrm{c}}$, and $K_{\mathrm{O}}$ are given by

$\Gamma^{*}=0.5\left[\mathrm{O}_{2}\right] / S$,

$K_{\mathrm{c}}=30 \times 2.1^{q_{\mathrm{t}}}$,

$K_{\mathrm{O}}=30000 \times 1.2^{q_{\mathrm{t}}}$,

$S=2600 \times 0.57^{q \mathrm{t}}$,

where $S$ is the ratio of the partition of RuBP to the carboxylase or oxygenase reactions of $\mathrm{RuBisCO}$.

$\bar{Q}_{x}$ in Eq. (74) is defined by the following equation:

$\bar{Q}_{x}=Q_{x} / L_{x}$

Here, $Q_{x}$ is the PAR absorbed by the entire canopy for sunlit ( $\left.Q_{\mathrm{sn}}\right)$ and shade $\left(Q_{\mathrm{sh}}\right)$ leaves. $Q_{\mathrm{sn}}$ and $Q_{\mathrm{sh}}$ consist of direct and scattered components and are given as

$Q_{\mathrm{sn}}=Q_{\mathrm{sn}, \mathrm{d}}+Q_{\mathrm{sn}, \mathrm{s}}$,
$Q_{\mathrm{sh}}=Q_{\mathrm{sh}, \mathrm{s}}$

where $Q_{\mathrm{sn}, \mathrm{d}}, Q_{\mathrm{sn}, \mathrm{s}}$, and $Q_{\mathrm{sh}, \mathrm{s}}$ are the direct PAR absorbed by sunlit leaves, the scattered PAR absorbed by sunlit leaves, and the scattered PAR absorbed by shade leaves, respectively. These are described by

$Q_{\mathrm{sn}, \mathrm{d}}=k_{\mathrm{q}} \int_{0}^{L} \frac{\mathrm{d} D_{1}^{\mathrm{d}}(l)}{\mathrm{d} l} \mathrm{~d} l$, 
$Q_{\mathrm{sn}, \mathrm{s}}=k_{\mathrm{q}} \int_{0}^{L} \frac{\mathrm{d}\left(S_{1}^{\mathrm{d}}(l)-S_{1}^{\mathrm{u}}(l)\right)}{\mathrm{d} l} f_{\mathrm{sn}}(l) \mathrm{d} l$,

$Q_{\mathrm{sh}, \mathrm{s}}=k_{\mathrm{q}} \int_{0}^{L} \frac{\mathrm{d}\left(S_{1}^{\mathrm{d}}(l)-S_{1}^{\mathrm{u}}(l)\right)}{\mathrm{d} l}\left(1-f_{\mathrm{sn}}(l)\right) \mathrm{d} l$,

where $D_{1}^{\mathrm{d}}(l), S_{1}^{\mathrm{d}}(l)$, and $S_{1}^{\mathrm{u}}(l)$ are calculated by the LSM (Eqs. 12-14) and $k_{\mathrm{q}}$ is a constant that transfers the radiant flux density to photon flux density.

$\bar{R}_{\mathrm{d}, x}$ in Eq. (64) is given by the following equation:

$\bar{R}_{\mathrm{d}, x}=f_{\mathrm{d}} \bar{V}_{\max , x}\left[2^{q_{\mathrm{t}}} /\left\{1+\exp \left(s_{5}\left(T_{\mathrm{c}}-s_{6}\right)\right)\right\}\right]$,

where $f_{\mathrm{d}}$ is a respiration factor and crop-specific parameter, whereas $s_{5}$ and $s_{6}$ are parameters that are not crop dependent. It should be noted that $\bar{A}_{\mathrm{n}, x}$ can be calculated using the equations described in this section (Eqs. 64-94) if $c_{\mathrm{i}, x}$ is given.

$\bar{A}_{\mathrm{n}, x}$ should be equal to the $\mathrm{CO}_{2}$ flux between the leaf interior and boundary layer and the $\mathrm{CO}_{2}$ flux between the leaf boundary layer and the atmosphere. If these requirements are fulfilled, the following equation can be derived:

$$
\begin{aligned}
\bar{A}_{\mathrm{n}, x} & =\left(\bar{g}_{1} / P_{\mathrm{a}}\right)\left(c_{\mathrm{a}}-c_{\mathrm{s}, x}\right) / 1.4 \\
& =\left(\bar{g}_{\mathrm{st}, x} / P_{\mathrm{a}}\right)\left(c_{\mathrm{s}, x}-c_{\mathrm{i}, x}\right) / 1.6,
\end{aligned}
$$

where $c_{\mathrm{a}}$ is the partial pressure of atmospheric $\mathrm{CO}_{2}, c_{\mathrm{s}, x}$ is the partial pressure of $\mathrm{CO}_{2}$ at the leaf boundary layer for sunlit and shade leaves, $\bar{g}_{1}$ is the leaf boundary conductance for vapour per unit leaf area, and $\bar{g}_{\text {st }, x}$ is the stomatal conductance for vapour per unit leaf area for sunlit and shade leaves. From Eq. (95), $c_{\mathrm{i}, x}$ and $c_{\mathrm{s}, x}$ are defined by

$c_{\mathrm{i}, x}=c_{\mathrm{a}}-\left(1.4 / \bar{g}_{1}+1.6 / \bar{g}_{\mathrm{st}, x}\right) \bar{A}_{\mathrm{n}, x} P_{\mathrm{a}}$,

$c_{\mathrm{s}, x}=c_{\mathrm{a}}-1.4 \bar{A}_{\mathrm{n}, x} P_{\mathrm{a}} / \bar{g}_{1}$.

The variables $c_{\mathrm{a}}$ and $\bar{g}_{1}$ are given by

$c_{\mathrm{a}}=\left(C_{\mathrm{a}, \mathrm{ppm}} \times 10^{-6}\right) P_{\mathrm{a}}$,

$\bar{g}_{1}=\left(\bar{g}_{\mathrm{a}} / 2\right) \times P_{\mathrm{a}} /\left(T_{\mathrm{c}} R_{\mathrm{vap}} \omega_{\mathrm{H}_{2} \mathrm{O}}\right)$,

$\bar{g}_{\mathrm{a}}=c_{\mathrm{h}} U_{\mathrm{c}}$,

where $w_{\mathrm{H}_{2} \mathrm{O}}$ is a constant for the molar weight of vapour, $\bar{g}_{\mathrm{a}}$ is the leaf boundary conductance for heat per unit leaf area (for both sides of the leaf), $c_{\mathrm{h}}$ is the leaf transfer coefficient for heat and is a crop-specific parameter, and $U_{\mathrm{c}}$ is the mean wind speed in the canopy (Appendix F). Note that Eqs. (99) and (100) are based on Maruyama and Kuwagata (2008), whereas the original MATSIRO uses $C_{H_{\mathrm{c}}} U / L$ instead of $\bar{g}_{\mathrm{a}} / 2$ in Eq. (99).

$\bar{A}_{\mathrm{n}, x}$ meets the Ball-Berry relationship (Ball, 1988), which describes the relationship between $\bar{A}_{\mathrm{n}, x}, \bar{g}_{\mathrm{st}, x}$, and other environmental conditions. The Ball-Berry relationship is given by

$\bar{g}_{\mathrm{st}, x}= \begin{cases}m \frac{\bar{A}_{\mathrm{n}, x} P_{\mathrm{a}}}{c_{\mathrm{s}, x}} h_{\mathrm{s}, x}+b & \left(\text { if } \bar{A}_{\mathrm{n}, x}>0\right), \\ b & \text { (otherwise) }\end{cases}$ where $m$ and $b$ are the slope and intercept of the Ball-Berry relationship, and $h_{\mathrm{s}, x}$ is the relative humidity at the leaf boundary. It is noteworthy that $b$ indicates the stomatal conductance when $\bar{A}_{\mathrm{n}, x}$ is equal to or less than zero (Baldocchi, 1994) and that the effect of water stress on $b$ is not considered in MATCRO-Rice. The variables $m$ and $b$ are crop-specific parameters, and $h_{\mathrm{s}, x}$ is defined by

$h_{\mathrm{s}, x}=e_{\mathrm{s}, x} / e_{\mathrm{sat}}\left(T_{\mathrm{c}}, P_{\mathrm{a}}\right)$,

where $e_{\mathrm{s}, x}$ is the vapour pressure at the leaf boundary and $e_{\mathrm{sat}}$ is the saturated vapour pressure. The variable $e_{\mathrm{s}, x}$ is expressed as

$e_{\mathrm{s}, x}=\left(e_{\mathrm{a}} \bar{g}_{1}+e_{\mathrm{i}} \bar{g}_{\mathrm{st}, x}\right) /\left(\bar{g}_{1}+\bar{g}_{\mathrm{st}, x}\right)$,

where $e_{\mathrm{a}}$ and $e_{\mathrm{i}}$ are the vapour pressure in the air and leaf, respectively. Equation (103) is derived from the fact that the water vapour flux from the stomata to the leaf surface is equal to the water vapour flux from the leaf surface into the atmosphere, which is shown in the following equation:

$\bar{g}_{\mathrm{st}, x}\left(e_{\mathrm{i}}-e_{\mathrm{s}, x}\right)=\bar{g}_{1}\left(e_{\mathrm{s}, x}-e_{\mathrm{a}}\right)$.

The parameters $e_{\mathrm{a}}, e_{\mathrm{i}}$, and $e_{\mathrm{sat}}$ are given by

$e_{\mathrm{a}}=Q\left(R_{\mathrm{vap}} / R_{\mathrm{dry}}\right) P_{\mathrm{a}}$,

$e_{\mathrm{i}}=e_{\mathrm{sat}}\left(T_{\mathrm{c}}, P_{\mathrm{a}}\right)$,

$e_{\text {sat }}\left(T_{\mathrm{c}}, P_{\mathrm{a}}\right)=Q_{\text {sat }}\left(T_{\mathrm{c}}, P_{\mathrm{a}}\right)\left(R_{\mathrm{vap}} / R_{\text {dry }}\right) P_{\mathrm{a}}$,

where $e_{\mathrm{i}}$ is assumed to be saturated.

Now we have three relationships (Eqs. 64-94, 96, and 101) in terms of three unknown variables $\left(\bar{A}_{\mathrm{n}, x}, c_{\mathrm{i}, x}\right.$, and $\left.\bar{g}_{\mathrm{st}, x}\right)$. Therefore, we can determine the values for $\bar{A}_{\mathrm{n}, x}, c_{\mathrm{i}, x}$, and $\bar{g}_{\text {st }, x}$, by numerically solving the three relationships. The numerical method is described in Masutomi et al. (2016).

Last, $\bar{g}_{\mathrm{s}}$ is given by the following equation:

$\bar{g}_{\mathrm{s}}=\bar{g}_{\mathrm{st}} \times\left(T_{\mathrm{c}} R_{\mathrm{vap}} w_{\mathrm{H}_{2} \mathrm{O}} / P_{\mathrm{a}}\right)$,

$\bar{g}_{\mathrm{st}}=\left\{\left(\bar{g}_{\mathrm{st}, \mathrm{sn}} \times L_{\mathrm{sn}}+\bar{g}_{\mathrm{st}, \mathrm{sh}} \times L_{\mathrm{sh}}\right) / L\right\} \times 2$,

where $\bar{g}_{\text {st }}$ is the stomatal conductance for vapour per unit leaf area for both sides of the leaf.

\subsection{Crop development}

The crop development module calculates $D_{\mathrm{vs}}$, which is an index used to quantify developmental stage of crops. $D_{\mathrm{vs}}$ is mainly used for determining the timing of transplanting, heading, and harvesting. In addition, $D_{\mathrm{vs}}$ is used for partitioning of carbon assimilation into each organ and for estimating LAI and height. This module is based on the formulation by Bouman et al. (2001). $D_{\mathrm{vs}}$ is calculated from

$D_{\mathrm{vs}}=G_{\mathrm{ds}} / G_{\mathrm{ds}, \mathrm{m}}$

$G_{\mathrm{ds}}=\int_{0}^{t} D_{\mathrm{vr}} \mathrm{d} t^{\prime}$ 


$$
D_{\mathrm{vr}}= \begin{cases}0 & \left(T_{\mathrm{a}}<T_{\mathrm{b}} \mid T_{\mathrm{h}} \leq T_{\mathrm{a}}\right) \\ T_{\mathrm{a}}-T_{0} & \left(T_{\mathrm{b}} \leq T_{\mathrm{a}}<T_{\mathrm{o}}\right), \\ \left(T_{\mathrm{o}}-T_{\mathrm{b}}\right)\left(T_{\mathrm{h}}-T_{\mathrm{a}}\right) /\left(T_{\mathrm{h}}-T_{\mathrm{o}}\right) & \left(T_{\mathrm{o}} \leq T_{\mathrm{a}}<T_{\mathrm{h}}\right),\end{cases}
$$

where $G_{\mathrm{ds}}$ is the growing degree seconds at $t, G_{\mathrm{ds}, \mathrm{m}}$ is $G_{\mathrm{ds}}$ required until maturation, $D_{\mathrm{vr}}$ is the development rate at $t$, $T_{0}$ is the melting temperature of water, and $T_{\mathrm{b}}, T_{\mathrm{h}}$, and $T_{\mathrm{o}}$ are the minimum temperature, maximum temperature, and optimal temperature for development, respectively. The value of $G_{\mathrm{ds}, \mathrm{m}}$ is parameterized in Masutomi et al. (2016), and $T_{\mathrm{b}}, T_{\mathrm{h}}$, and $T_{\mathrm{O}}$ are crop-specific parameters. $T_{0}$ is a physical constant (Table 5). It should be noted that $D_{\mathrm{vs}}=0$ represents sowing and $D_{\mathrm{vs}}=1$ represents maturation. Furthermore, we introduce two parameters that represent the timing of emergence ( $\left.D_{\mathrm{vs}, \mathrm{e}}\right)$ and heading $\left(D_{\mathrm{vs}, \mathrm{h}}\right)$. Both $D_{\mathrm{vs}, \mathrm{e}}$ and $D_{\mathrm{vs}, \mathrm{h}}$ are cropspecific parameters. The values of $D_{\mathrm{vs}, \mathrm{e}}$ and $D_{\mathrm{vs}, \mathrm{h}}$ are parameterized in Masutomi et al. (2016). Crop simulation start at the day of sowing $\left(D_{\mathrm{oy}, \mathrm{sw}}\right)$ which is a simulation setting parameter.

During the transplantation of rice seedlings, the seedlings enter transplanting shock, which prevents shoot growth (Bouman et al., 2001). In MATCRO-Rice, the transplanting shock period is defined by $D_{\mathrm{vs}}$, where $D_{\mathrm{vs}}$, tr is $D_{\mathrm{vs}}$ at the time when transplanting shock starts and $D_{\mathrm{vs}}$, te is $D_{\mathrm{vs}}$ at which transplanting shock ends. Both $D_{\mathrm{vs}, \text { tr }}$ and $D_{\mathrm{vs} \text {, te }}$ are parameterized in Masutomi et al. (2016).

\subsection{Crop growth}

This module calculates the growth of organs and reserves. The organs considered in MATCRO-Rice include the leaf, stem, panicle, and root. In addition, the model considers glucose reserves in leaves and starch reserves in stems. All carbon assimilated in leaves through photosynthesis is first stored in the leaf in the form of glucose. Then, the stored glucose is partitioned to each organ and stored in the stem when the amount of the stored glucose exceeds the critical rate to dry weight of the leaf. This module is based on MACROS (Penning de Vries et al., 1989).

The dry weights of each organ and reserve are expressed by

$$
\begin{aligned}
& W_{\text {lef }}=W_{\text {lef }, 0}+\int_{t_{\mathrm{e}}}^{t}\left(G_{\mathrm{r}, \text { lef }}-L_{\mathrm{s}, \text { lef }}\right) \mathrm{d} t^{\prime}, \\
& W_{\mathrm{stm}}=W_{\mathrm{stm}, 0}+\int_{t_{\mathrm{e}}}^{t} G_{\mathrm{r}, \mathrm{stm}} \mathrm{d} t^{\prime}, \\
& W_{\mathrm{pnc}}=\int_{t_{\mathrm{e}}}^{t} G_{\mathrm{r}, \mathrm{pnc}} \mathrm{d} t^{\prime} \\
& W_{\text {rot }}=W_{\mathrm{rot}, 0}+\int_{t_{\mathrm{e}}}^{t} G_{\mathrm{r}, \mathrm{rot}} \mathrm{d} t^{\prime},
\end{aligned}
$$

$W_{\mathrm{stc}}=\int_{t_{\mathrm{e}}}^{t}\left(G_{\mathrm{r}, \mathrm{stc}}-R_{\mathrm{m}, \mathrm{stc}}\right) \mathrm{d} t^{\prime}$

$W_{\text {glu }}=W_{\text {glu }, 0}+\int_{t_{\mathrm{e}}}^{t} G_{\mathrm{r}, \mathrm{glu}} \mathrm{d} t^{\prime}$,

where $W_{\text {lef }}, W_{\text {stm }}, W_{\text {pnc }}, W_{\text {rot }}, W_{\text {stc }}$, and $W_{\text {glu }}$ are the dry weight of leaves, stems, panicles, roots, starch reserves, and glucose reserves at $t$, respectively; $W_{\text {lef }, 0}, W_{\text {stm }, 0}, W_{\text {rot }, 0}$, and $W_{\mathrm{glu}, 0}$ represent the initial dry weight at emergence of each organ and reserve; $G_{\mathrm{r}, \text { lef }}, G_{\mathrm{r}, \mathrm{stm}}, G_{\mathrm{r}, \mathrm{pnc}}, G_{\mathrm{r}, \text { rot }}, G_{\mathrm{r}, \mathrm{stc}}$, and $G_{\mathrm{r}, \text { glu }}$ are the growth rates of the corresponding organ and reserve; $L_{\mathrm{s}, \text { lef }}$ is the loss rate of leaves due to leaf death; $R_{\mathrm{m} \text {,stc }}$ is the loss rate of starch reserves in the stem due to remobilization; $t_{\mathrm{e}}$ is the time at emergence after sowing; and $W_{\text {lef, } 0}$, $W_{\text {stm }, 0}, W_{\text {rot, } 0}$, and $W_{\text {glu }, 0}$ are simulation setting parameters.

The glucose reserve in the leaf is supplied through photosynthesis in leaves and remobilization from the stem. Thus, the supply of glucose is given by

$S_{\mathrm{glu}}=A_{\mathrm{n}} C_{\mathrm{CO}_{2}, \mathrm{glu}}+R_{\mathrm{m}, \mathrm{stc}} C_{\mathrm{stc}, \mathrm{glu}}$,

where $S_{\mathrm{glu}}$ is the supply of glucose to the leaf reserve, $A_{\mathrm{n}}$ is the net carbon assimilation calculated in Eq. (63), and $C_{\mathrm{CO}_{2} \text {,glu }}$ and $C_{\text {stc, glu }}$ are the conversion factors from $\mathrm{CO}_{2}$ or starch to glucose, which are chemically determined (Table 5). We assumed that the partition of glucose in leaves to each organ occurs if the following equation is met:

$W_{\mathrm{glu}}+S_{\mathrm{glu}} \delta t>k_{\mathrm{glu}} W_{\mathrm{lef}}$,

where $\delta t$ is one simulation time step, $k_{\text {glu }}$ is the critical ratio at which the partition of glucose happens, and $\delta t$ is a simulation setting parameter. We set $k_{\mathrm{glu}}=0.1$ (Penning de Vries et al., 1989). When Eq. (120) is met, the amount of glucose that exceeds the critical ratio is partitioned to each organ and reserve according to the following equation:

$G_{\mathrm{p}, \mathrm{glu}}=\left(W_{\mathrm{glu}}+S_{\mathrm{glu}} \delta t-k_{\mathrm{glu}} W_{\mathrm{lef}}\right) / \delta t$,

where $G_{\mathrm{p}, \mathrm{glu}}$ is the amount of glucose partitioned to each organ and reserve. The growth rate of each organ and reserve is expressed as follows:

$$
\begin{aligned}
G_{\mathrm{r}, \text { lef }}= & G_{\mathrm{p}, \mathrm{glu}} P_{\mathrm{r}, \mathrm{sh}} P_{\mathrm{r}, \text { lef }} C_{\mathrm{glu}, \text { lef }}, \\
G_{\mathrm{r}, \mathrm{stm}}= & G_{\mathrm{p}, \mathrm{glu}} P_{\mathrm{r}, \mathrm{sh}}\left(1-P_{\mathrm{r}, \text { lef }}-P_{\mathrm{r}, \mathrm{pnc}}\right) \\
& \times\left(1-f_{\mathrm{stc}}\right) C_{\mathrm{glu}, \mathrm{stm}}, \\
G_{\mathrm{r}, \mathrm{pnc}}= & G_{\mathrm{p}, \mathrm{glu}} P_{\mathrm{r}, \mathrm{sh}} P_{\mathrm{r}, \mathrm{pnc}} C_{\mathrm{glu}, \mathrm{pnc}}, \\
G_{\mathrm{r}, \mathrm{rot}}= & G_{\mathrm{p}, \mathrm{glu}}\left(1-P_{\mathrm{r}, \mathrm{sh}}\right) C_{\mathrm{glu}, \mathrm{rot}}, \\
G_{\mathrm{r}, \mathrm{stc}}= & G_{\mathrm{p}, \mathrm{glu}} P_{\mathrm{r}, \mathrm{sh}}\left(1-P_{\mathrm{r}, \text { lef }}-P_{\mathrm{r}, \mathrm{pnc}}\right) f_{\mathrm{stc}} C_{\mathrm{glu}, \mathrm{stc}}, \\
G_{\mathrm{r}, \mathrm{glu}}= & \left(k_{\mathrm{glu}} W_{\mathrm{lef}}-W_{\mathrm{glu}}\right) / \delta t,
\end{aligned}
$$

where $P_{\mathrm{r} \text {,sh }}$ is the ratio of glucose partitioned to the shoot; $P_{\mathrm{r}, \text { lef }}$ and $P_{\mathrm{r}, \mathrm{pnc}}$ are the partition ratios of glucose from the 
shoot to the leaf and panicle; $f_{\text {stc }}$ is the proportion of glucose allocated to starch reserve in the stem; and $C_{\mathrm{glu}, \text { lef }}, C_{\mathrm{glu}, \mathrm{stm}}$, $C_{\mathrm{glu}, \text { rot }}, C_{\mathrm{glu}, \mathrm{pnc}}$, and $C_{\mathrm{glu}, \text { stc }}$ are dry weight of corresponding organs and reserves that are produced from the unit weight of glucose. $f_{\mathrm{stc}}, C_{\mathrm{glu}, \text { lef }}, C_{\mathrm{glu}, \mathrm{stm}}, C_{\mathrm{glu}, \text { rot }}$, and $C_{\mathrm{glu}, \mathrm{pnc}}$ are cropspecific parameters. $f_{\text {stc }}$ is parameterized in Masutomi et al. (2016). We set the values of $C_{\mathrm{glu}, \text { lef }}, C_{\mathrm{glu}, \mathrm{stm}}, C_{\mathrm{glu}, \text { rot }}$, and $C_{\text {glu,pnc }}$ according to Penning de Vries et al. (1989). $C_{\text {glu,stc }}$ is a chemical constant. If Eq. (120) is not met, glucose is not partitioned into each organ and reserve, except as the glucose reserve in the leaf. Therefore, the growth rate of each organ and reserve are calculated as follows:

$G_{\mathrm{r}, \text { lef }}=G_{\mathrm{r}, \mathrm{stm}}=G_{\mathrm{r}, \mathrm{rot}}=G_{\mathrm{r}, \mathrm{pnc}}=G_{\mathrm{r}, \mathrm{stc}}=0$

$G_{\mathrm{r}, \mathrm{glu}}=S_{\mathrm{glu}}$

The partition ratios to each organ are given as

$$
\begin{aligned}
& P_{\mathrm{r}, \mathrm{sh}}= \begin{cases}1-P_{\mathrm{rot}} & \left(D_{\mathrm{vs}} \leq D_{\mathrm{vs}, \mathrm{tr}}\right) \\
0 & \left(D_{\mathrm{vs}, \mathrm{tr}}<D_{\mathrm{vs}} \leq D_{\mathrm{vs}, \mathrm{te}}\right) \\
1-P_{\mathrm{rot}} & \left(D_{\mathrm{vs}, \mathrm{te}}<D_{\mathrm{vs}} \leq D_{\mathrm{vs}, \mathrm{rot} 1}\right) \\
\frac{1-P_{\mathrm{rot}}\left(D_{\mathrm{vs}, \mathrm{rot} 1}-D_{\mathrm{vs}}\right)}{\left(D_{\mathrm{v} s \text { rot }}-D_{\mathrm{vs}, \mathrm{rot} 1}\right)} & \left(D_{\left.\mathrm{vs}, \text { rot } 1<D_{\mathrm{vs}} \leq D_{\mathrm{vs}, \mathrm{rot} 2}\right)}\right) \\
1 & (\text { otherwise })\end{cases}
\end{aligned}
$$

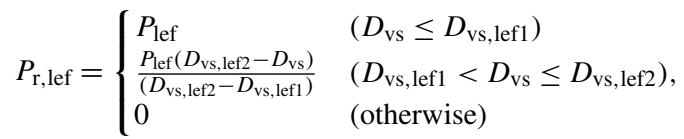

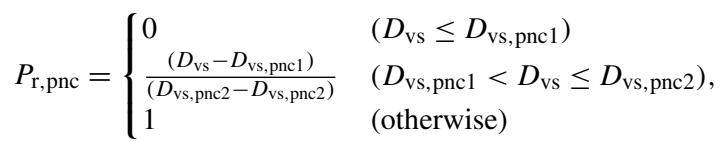

where $D_{\mathrm{vs}, \text { rot1 }}, D_{\mathrm{vs}, \text { rot2 }}, D_{\mathrm{vs}, \text { lef1 },} D_{\mathrm{vs}, \text { lef2 },} D_{\mathrm{vs}, \text { pnc1 }}$, and $D_{\mathrm{vs}, \mathrm{pnc} 2}$ represent the $D_{\mathrm{vs}}$ values at which corresponding partitions change; $P_{\text {rot }}$ is the ratio of partitioned glucose to the roots at $D_{\mathrm{vs}}<D_{\mathrm{vs}, \text { rot } 1}$; and $P_{\text {lef }}$ is the ratio of glucose partitioned to the leaf and glucose partitioned to the shoot at $D_{\mathrm{vs}}<D_{\mathrm{vs}, \text { lef1 }} . D_{\mathrm{vs}, \text { rot1 } 1}, D_{\mathrm{vs}, \text { rot2 } 2}, D_{\mathrm{vs}, \text { lef1 }}, D_{\mathrm{vs}, \text { lef2 }}, D_{\mathrm{vs}, \text { pnc1 }}$, $D_{\text {vs,pnc2 }}, P_{\text {rot }}$, and $P_{\text {lef }}$ are crop-specific parameters and are parameterized in Masutomi et al. (2016). In Eq. (130), we assume that no glucose is partitioned to the shoot during transplanting shock ( $D_{\mathrm{vs}, \text { tr }}<D_{\mathrm{vs}} \leq D_{\mathrm{vs}, \text { te }}$ ). It is important to note that transplanting shock is considered only when transplanting is conducted.

Loss of leaf dry weight due to leaf death $\left(L_{\mathrm{s}, \text { lef }}\right)$ and remobilization from starch reserve in the stem $\left(R_{\mathrm{m}, \mathrm{stm}}\right)$ occur after heading and they are defined as follows:

$$
\begin{aligned}
& L_{\mathrm{s}, \text { lef }}= \begin{cases}0 & \left(D_{\mathrm{vs}} \leq D_{\mathrm{vs}, \mathrm{h}}\right), \\
r_{\mathrm{dd}, \text { lef }}\left(W_{\text {lef }}+W_{\mathrm{glu}}\right) & (\text { otherwise })\end{cases} \\
& R_{\mathrm{m}, \mathrm{stc}}= \begin{cases}0 & \left(D_{\mathrm{vs}} \leq D_{\mathrm{vs}, \mathrm{h}}\right), \\
r_{\mathrm{rm}, \mathrm{stc}} W_{\mathrm{stc}} & (\text { otherwise })\end{cases}
\end{aligned}
$$

where $r_{\mathrm{dd} \text {,lef }}$ and $r_{\mathrm{rm}, \mathrm{stc}}$ represent the ratios of leaf death and remobilization. $r_{\mathrm{dd}, \text { lef }}$ varies with $D_{\mathrm{vs}}$ as follows:

$r_{\mathrm{dd}, \text { lef }}=r_{\mathrm{d} 1, \mathrm{lef}}\left(D_{\mathrm{vs}}-D_{\mathrm{vs}, \mathrm{h}}\right) /\left(1-D_{\mathrm{vs}, \mathrm{h}}\right)$, where $r_{\mathrm{d} 1 \text {,lef }}$ is the ratio of leaf death at harvest $\left(D_{\mathrm{vs}}=1\right)$ and it is parameterized in Masutomi et al. (2016). We set $r_{\mathrm{rm}, \mathrm{stc}}=1.16 \times 10^{-6}$, assuming that all starch stored in the stem is remobilized in 10 days after heading (Bouman et al., 2001).

Last, the dry weight of the shoot $\left(W_{\mathrm{sh}}\right)$, used in Sect. 3.4, is given by

$W_{\mathrm{sh}}=W_{\mathrm{lef}}+W_{\mathrm{stm}}+W_{\mathrm{pnc}}+W_{\mathrm{stc}}+W_{\mathrm{glu}}$.

\subsection{LAI, crop height, and root depth}

Leaf area index $(L)$, crop height $\left(h_{\mathrm{gt}}\right)$, and root depth $\left(z_{\mathrm{rt}}\right)$ are expressed as

$$
\begin{aligned}
& L=\left(W_{\mathrm{lef}}+W_{\mathrm{glu}}\right) / S_{\mathrm{lw}}, \\
& S_{\mathrm{lw}}=S_{\mathrm{lw}, \mathrm{mx}}+\left(S_{\mathrm{lw}, \mathrm{mn}}-S_{\mathrm{lw}, \mathrm{mx}}\right) \exp \left(-k_{S_{\mathrm{lw}}} D_{\mathrm{vs}}\right), \\
& h_{\mathrm{gt}}= \begin{cases}h_{\mathrm{aa}} L^{h_{\mathrm{ab}}} & \left(D_{\mathrm{vs}}<D_{\mathrm{vs}, \mathrm{h}}\right), \\
h_{\mathrm{ba}} L^{h_{\mathrm{bb}}} & \left(D_{\mathrm{vs}, \mathrm{h}}<D_{\mathrm{vs}}\right)\end{cases} \\
& z_{\mathrm{rt}}=\min \left\{z_{\mathrm{rt}, \mathrm{mx}}, r_{\mathrm{rt}}\left(t-t_{\mathrm{e}}\right)\right\},
\end{aligned}
$$

where $S_{\mathrm{lw}}$ is the specific leaf weight; $S_{\mathrm{lw}, \mathrm{mx}}$ and $S_{\mathrm{lw}, \mathrm{mn}}$ are the maximum and minimum values of specific leaf weight, respectively; $k_{S_{\mathrm{lw}}}$ is a parameter that determines the relationship between $D_{\text {vs }}$ and specific leaf weight; $h_{\mathrm{aa}}, h_{\mathrm{ab}}, h_{\mathrm{ba}}$, and $h_{\mathrm{bb}}$ are parameters that define the relationship between LAI and crop height; $z_{\mathrm{rt}, \mathrm{mx}}$ is the maximum root depth; and $r_{\mathrm{rt}}$ is the root growth rate. The allometric equations for estimating crop height (Eq. 139) is based on Maruyama and Kuwagata (2010). $S_{\mathrm{lw}, \mathrm{mx}}, S_{\mathrm{lw}, \mathrm{mn}}, k_{S_{\mathrm{lw}}}, h_{\mathrm{aa}}, h_{\mathrm{ab}}, h_{\mathrm{ba}}$, and $h_{\mathrm{bb}}$ are crop-specific parameters; they are parameterized in Masutomi et al. (2016). $z_{\mathrm{rt}, \mathrm{mx}}$ and $r_{\mathrm{rt}}$ are also crop-specific parameters, and they are set to $z_{\mathrm{rt}, \mathrm{mx}}=0.3$ and $r_{\mathrm{rt}}=1.16 \times 10^{-7}$ $\left(=0.01 \mathrm{~m} \mathrm{day}^{-1}\right)$ (Penning de Vries et al., 1989).

\subsection{Crop yield}

Crop yield is calculated from dry weight of the panicle at maturity as follows:

$Y_{\mathrm{ld}}=k_{\mathrm{yld}} W_{\mathrm{pnc}, \mathrm{mt}}$,

where $Y_{\mathrm{ld}}$ is the crop yield, $W_{\mathrm{pnc}, \mathrm{mt}}$ is the dry weight of the panicle at maturity, and $k_{\mathrm{yld}}$ is the ratio of the crop yield to $W_{\mathrm{pnc}, \mathrm{mt}}$. The variable $k_{\mathrm{yld}}$ is a crop-specific parameter and it is parameterized in Masutomi et al. (2016).

\section{Concluding remarks}

We developed a new LSM-CGM combined model for paddy rice fields called MATCRO-Rice, which is fully described in the present paper. MATCRO-Rice has two features: (i) the model can consistently simulate LHF, SHF, biomass growth for each organ, and crop yield by exchanging variables listed 
in Table 2; (ii) the model considers water surface and irrigation in paddy rice fields. According to our literature survey, MATCRO-Rice is the first LSM-CGM combined model for rice that employs these two features.

The first feature enables us to apply the model to a wide range of integrated issues. For example, by using MATCRORice, we can assess the impacts of paddy rice fields on climate through heat and water fluxes and consistently assess the impacts of climate on rice productivity. Osborne et al. (2009) showed that the interaction between agricultural land and climate can play an important role in the annual variability of both the climate and crop yield. MATCRO-Rice can investigate the impact of the interactions at paddy rice fields on climate and rice productivity. MATCRO-Rice can be a useful tool for addressing the integrated issues of agriculture and hydrology.

MATCRO-Rice can be also applied to simultaneously assess the climate change impacts on rice productivity and hydrological cycle in paddy rice fields. Masutomi et al. (2009) showed that climate change will have significant impact on rice productivity across Asia. In addition, agricultural land is one of the key players in global hydrological cycle, and climate change will globally alter the hydrological cycle (Oki and Kanae, 2006).
The first feature also gives us a chance to comprehensively evaluate the model with observations (Lei et al., 2010). Model evaluation is described in the companion paper (Masutomi et al., 2016).

The current version (v. 1) of MATCRO-Rice has a major limitation. Nitrogen dynamics is not included in MATCRORice, although it is well known that nitrogen stress significantly affects crop growth, and hence LHF and SHF. This indicates that MATCRO-Rice simulates LHF, SHF, biomass growth, and crop yield with no nitrogen stress. To apply the model to the site with nitrogen stress, it is necessary to include nitrogen dynamics. This feature is an important future challenge.

\section{Code and data availability}

The source code of MATCRO will be distributed by request to the corresponding author (Yuji Masutomi: yuji.masutomi@gmail.com). The website for MATCRORice will be developed in the near future. 


\section{Appendix A: $\rho_{\mathrm{a}}$ and $Q_{\text {sat }}$}

The air density $\left(\rho_{\mathrm{a}}\right)$ and the specific humidity at saturation $\left(Q_{\text {sat }}\right)$ are calculated physically according to the equation for the state of dry air and the Clausius-Clapeyron equation, respectively, as follows:

$$
\begin{aligned}
& \rho_{\mathrm{a}}=P_{\mathrm{a}} /\left(R_{\mathrm{dry}} T_{\mathrm{a}}\right), \\
& Q_{\text {sat }}\left(T_{x}, P_{\mathrm{a}}\right)=\left(R_{\text {dry }} / R_{\text {vap }}\right)\left\{e _ { \text { sat } } ( T _ { 0 } ) \operatorname { e x p } \left(\left(\lambda / R_{\text {vap }}\right)\right.\right. \\
& \left.\left.\left(1 / T_{0}-1 / T_{x}\right)\right)\right\} / P_{\mathrm{a}},
\end{aligned}
$$

where $T_{\mathrm{a}}$ is air temperature; $P_{\mathrm{a}}$ is air pressure; $T_{x}$ is temperature of the canopy $\left(T_{\mathrm{c}}\right)$ or surface $\left(T_{\mathrm{g}}\right) ; T_{0}$ is the melting temperature of the water; $R_{\text {dry }}$ and $R_{\text {vap }}$ are the gas constants of the dry air and vapour, respectively; $e_{\text {sat }}\left(T_{0}\right)$ is the vapour pressure at melting temperature of the water; and $\lambda$ is the latent heat of vaporization. $T_{\mathrm{a}}$ and $P_{\mathrm{a}}$ are meteorological inputs (Table 1). $T_{x}\left(T_{\mathrm{c}}\right.$ or $\left.T_{\mathrm{g}}\right)$ is calculated in Sect. 3.1. The other parameters are physical constants (Table 5).

\section{Appendix B: Zenith angle $\theta$}

According to Goudriaan and van Laar (1994), the zenith angle of the $\operatorname{sun}(\theta)$ is calculated as follows:

$$
\begin{aligned}
\cos (\theta) & =\sin \left(2 \pi L_{\mathrm{t}} / 360\right) \sin \left(\delta_{\mathrm{s}}\right)+\cos \left(2 \pi L_{\mathrm{t}} / 360\right) \\
& \times \cos \left(\delta_{\mathrm{s}}\right) \cos \left(h_{\mathrm{arg}}\right), \\
\delta_{\mathrm{s}}= & -\arcsin (\sin (23.45(2 \pi / 360)) \\
\quad & \left.\times \cos \left(2 \pi\left(D_{\mathrm{oy}}+10\right) / 365\right)\right), \\
h_{\mathrm{arg}}= & 2 \pi\left(h_{\mathrm{r}}-12\right) / 24,
\end{aligned}
$$

where $L_{\mathrm{t}}$ is the latitude in radians at the simulation site, $\delta_{\mathrm{s}}$ is the declination of the sun, $h_{\mathrm{arg}}$ is the hour angle from noon $\left(h_{\mathrm{r}}=12\right), D_{\text {oy }}$ is the number of days from 1 January at the simulation site, and $h_{\mathrm{r}}$ is the local time at the simulation site.

\section{Appendix C: Coefficients for radiation equations}

The coefficients for radiation equations (Eqs. 12-14) are calculated as follows:

$$
\begin{aligned}
a_{i}= & F d_{\mathrm{f}}\left\{\left(1-t_{i}\right)^{2}-r_{i}^{2}\right\}^{1 / 2}, \\
C_{1, i}= & \left\{-\left(A_{2, i}-r_{\mathrm{g}}\right)\left(S_{i}^{\mathrm{d}}(0)-C_{3, i} D_{i}^{\mathrm{d}}(0)\right) \exp \left(-a_{i} L\right)\right. \\
& \left.\left.+\left(C_{3, i} r_{\mathrm{g}}+r_{\mathrm{g}}-C_{4, i}\right) D_{i}^{\mathrm{d}}(0) \exp (-F L \sec (\theta))\right)\right\} \\
& / A_{3, i}, \\
C_{2, i}= & \left\{\left(A_{1, i}-r_{\mathrm{g}}\right)\left(S_{i}^{\mathrm{d}}(0)-C_{3, i} D_{i}^{\mathrm{d}}(0)\right) \exp \left(a_{i} L\right),\right. \\
& \left.-\left(C_{3, i} r_{\mathrm{g}}+r_{\mathrm{g}}-C_{4, i}\right) D_{i}^{\mathrm{d}}(0) \exp (-F L \sec (\theta))\right\} \\
& / A_{3, i}, \\
C_{3, i}= & \sec (\theta)\left\{t_{i} \sec (\theta)+d_{\mathrm{f}} t_{i}\left(1-t_{i}\right)+d_{\mathrm{f}} r_{i}^{2}\right\} \\
& /\left\{d_{\mathrm{f}}^{2}\left(\left(1-t_{i}\right)^{2}-r_{i}^{2}\right)-\sec ^{2}(\theta)\right\},
\end{aligned}
$$

$$
\begin{aligned}
C_{4, i} & \left.=\left\{r_{i}\left(d_{\mathrm{f}}-\sec (\theta)\right) \sec (\theta)\right)\right\} /\left\{d_{\mathrm{f}}^{2}\left(\left(1-t_{i}\right)^{2}-r_{i}^{2}\right)\right. \\
& \left.-\sec ^{2}(\theta)\right\}, \\
A_{1, i} & =\left(1-t_{i}+\left\{\left(1-t_{i}\right)^{2}-r_{i}^{2}\right\}^{1 / 2}\right) / r_{i}, \\
A_{2, i} & =\left(1-t_{i}-\left\{\left(1-t_{i}\right)^{2}-r_{i}^{2}\right\}^{1 / 2}\right) / r_{i}, \\
A_{3, i} & =\left(A_{1, i}-r_{\mathrm{g}}\right) \exp \left(a_{i} L\right)-\left(A_{2, i}-r_{\mathrm{g}}\right) \exp \left(-a_{i} L\right),
\end{aligned}
$$

where $i$ indicates the wavebands of radiation $(i=1$ : PAR; $i=2$ : NIR); $r_{i}$ and $t_{i}$ are the leaf reflectivity and transmissivity, respectively; $F$ is the distribution of leaf orientation; $d_{\mathrm{f}}$ is a scattering factor; $A_{3, i}$ is a new variable introduced in Eqs. (C2) and (C3); $L$ is the LAI; $r_{\mathrm{g}}$ is the surface albedo for shortwave radiation; $D_{i}^{\mathrm{d}}(0)$ and $S_{i}^{\mathrm{d}}(0)$ are direct and scattered downward radiant flux density at the canopy top, respectively; and $\theta$ is the zenith angle of the sun. $r_{i}$ and $t_{i}$ are cropspecific parameters determined by Sellers et al. (1996b). $F$ is set to 0.5 from the assumption of random leaf orientation (Goudriaan and van Laar, 1994), and $d_{\mathrm{f}}$ is $\sec (2 \pi(53 / 360))$ (Watanabe and Ohtani, 1995). $A_{3, i}$ is defined in Eq. (C8), $L$ is calculated in the CGM (Eq. 137), and $r_{\mathrm{g}}$ for surface is given in Maruyama and Kuwagata (2010). $D_{i}^{\mathrm{d}}(0)$ and $S_{i}^{\mathrm{d}}(0)$ are given in Eqs. (15) and (16), respectively, and $\theta$ is calculated in Eq. (B1).

It should be noted that $a_{i}, A_{1, i}$, and $A_{2, i}$ are not variables determined by constant parameters, while $C_{1, i}, C_{2, i}, C_{3, i}$, $C_{4, i}$, and $A_{3, i}$ are variables.

\section{Appendix D: Reflectivity and transmissivity of canopies}

Reflectivity $\left(r_{i j}\right)$ and transmissivity $\left(\tau_{i j}\right)$ of canopy for each waveband ( $i=1$ : PAR, $i=2$ : NIR) and for each direction ( $j=1$ : direct, $j=2$ : scattered) are given as follows:

$$
\begin{aligned}
r_{i 1}= & C_{4, i}-C_{3, i} r_{i 2}, \\
r_{i 2}= & \left(A_{1, i} C_{1, i}+A_{2, i} C_{2, i}\right) /\left(C_{1, i}+C_{2, i}\right), \\
\tau_{i 1}= & \left(1+C_{3, i}-C_{4, i} \exp (-F L \sec (\theta))\right)-C_{3, i} \tau_{i 2}, \\
\tau_{i 2}= & \left\{\left(C_{1, i}\left(1-A_{1, i}\right) \exp \left(a_{i} L\right)\right)\right. \\
& \left.+C_{2, i}\left(1-A_{2, i} \exp \left(-a_{i} L\right)\right)\right\} /\left(C_{1, i}+C_{2, i}\right),
\end{aligned}
$$

where $a_{i}, C_{1, i}, C_{2, i}, C_{3, i}, C_{4, i}, A_{1, i}$, and $A_{2, i}$, the coefficients of radiation equations (Eqs. 12-14), are calculated as shown in Appendix $C, F$ is a parameter that defines the distribution of leaf orientation, $L$ is the LAI, which is calculated in the CGM (Eq. 137), and $\theta$ is the zenith angle of the sun (Appendix B).

\section{Appendix E: $d, z_{M}, z_{T}, z_{Q}, z_{M \mathrm{~g}}$, and $z_{T \mathrm{~g}}$}

Zero-plane displacement height $(d)$, roughness lengths of an entire surface for the profiles of momentum, temperature, and specific humidity $\left(z_{M}, z_{T}\right.$, and $\left.z_{Q}\right)$, and roughness lengths that express the effect of surface on the profiles of momentum 
and temperature $\left(z_{M \mathrm{~g}}\right.$ and $\left.z_{T \mathrm{~g}}\right)$ are calculated according to Watanabe (1994) as follows:

$$
\begin{aligned}
& d=h_{\mathrm{gt}}\left[1-\frac{1}{A^{+}}\left\{1-\exp \left(-A^{+}\right)\right\}\right], \\
& \left(\ln \frac{h_{\mathrm{gt}}-d}{z_{M}}\right)^{-1}=\left\{1-\exp \left(-A^{+}\right)\right. \\
& \left.+\left(-\ln \frac{z_{M \mathrm{~s}}}{h_{\mathrm{gt}}}\right)^{-1 / 0.45} \exp \left(-2 A^{+}\right)\right\}^{0.45}, \\
& \left(\ln \frac{h_{\mathrm{gt}}-d}{z_{M}}\right)^{-1}\left(\ln \frac{h_{\mathrm{gt}}-d}{z_{X}}\right)^{-1}= \\
& =C_{X}^{\infty}\left\{1-\exp \left(-P_{3 X} A^{+}\right)+\left(\frac{C_{X}^{0}}{C_{X}^{\infty}}\right)^{1 / 0.9}\right. \\
& \left.\times \exp \left(-P_{4 X} A^{+}\right)\right\}^{0.9}, \\
& \left(\ln \frac{h_{\mathrm{gt}}-d}{z_{M \mathrm{~g}}}\right)^{2}=\left(\ln \frac{h_{\mathrm{gt}}-d}{z_{M}}\right)\left(\ln \frac{h_{\mathrm{gt}}-d}{z_{M}^{+}}\right), \\
& \left(\ln \frac{h_{\mathrm{gt}}-d}{z_{M \mathrm{~g}}}\right)\left(\ln \frac{h_{\mathrm{gt}}-d}{z_{T \mathrm{~g}}}\right)=\left(\ln \frac{h_{\mathrm{gt}}-d}{z_{M}}\right)\left(\ln \frac{h_{\mathrm{gt}}-d}{z_{T}^{+}}\right), \\
& A^{+}=\frac{c_{\mathrm{m}} L}{2 \kappa^{2}}, \\
& C_{X}^{0}=\left(\ln \frac{h_{\mathrm{gt}}-d}{z_{M}}\right)^{-1}\left(\ln \frac{h_{\mathrm{gt}}-d}{z_{X}^{+}}\right)^{-1}, \\
& C_{X}^{\infty}=\frac{-1+\left(1+8 F_{X}\right)^{0.5}}{2}, \\
& F_{X}=\frac{c_{X}}{c_{\mathrm{m}}}, \\
& \left(\ln \frac{h_{\mathrm{gt}}-d}{z_{*}^{+}}\right)^{-1}=\frac{1}{-\ln \left(\frac{z_{* \mathrm{~s}}}{h_{\mathrm{gt}}}\right)}\left(\frac{P_{1 *}}{P_{1 *}+A^{+} \exp \left(A^{+}\right)}\right)^{P_{2 *}}, \\
& P_{1 *}=0.00115\left(\frac{z_{* \mathrm{~s}}}{h_{\mathrm{gt}}}\right)^{0.1} \exp \left\{5\left(\frac{z_{* \mathrm{~s}}}{h_{\mathrm{gt}}}\right)\right\} \text {, }
\end{aligned}
$$

$$
\begin{aligned}
& P_{2 *}=0.55 \exp \left\{-0.58\left(\frac{z_{* \mathrm{~s}}}{h_{\mathrm{gt}}}\right)^{0.35}\right\}, \\
& P_{3 X}=\left\{F_{X}+0.084 \exp \left(-15 F_{X}\right)\right\}^{0.15}, \\
& P_{4 X}=2 F_{X}^{1.1}, \\
& c_{\mathrm{e}}=c_{\mathrm{h}} /\left(1+c_{\mathrm{h}}\left(U_{\mathrm{c}} / \bar{g}_{\mathrm{s}}\right)\right) .
\end{aligned}
$$

Here, $z_{M \mathrm{~s}}, z_{T \mathrm{~s}}$, and $z_{Q \mathrm{~s}}$ are the roughness lengths of surface for momentum, temperature, and specific humidity, respectively. In this model, we assume $z_{M \mathrm{~s}}, z_{T \mathrm{~s}}$, and $z_{Q \mathrm{~s}}=0.001 \mathrm{~m}$ (Kimura and Kondo, 1998). $c_{\mathrm{m}}, c_{\mathrm{h}}$, and $c_{\mathrm{e}}$ are the leaf transfer coefficients for momentum, temperature, and specific humidity, respectively. $c_{\mathrm{m}}$ an $c_{\mathrm{h}}$ are crop-specific parameters, while $c_{\mathrm{e}}$ is calculated in Eq. (E15). $h_{\mathrm{gt}}$ and $L$ are crop height and LAI, respectively, and are calculated in the CGM (Eqs. 139 and 137). $\bar{g}_{\mathrm{s}}$ is the stomatal conductance per unit leaf area for both sides of the leaf (Eq. 108). $U_{\mathrm{c}}$ is the mean wind speed in the canopy and is calculated in Appendix F. $A^{+}, C_{X}^{0}, C_{X}^{\infty}$, $z_{M}^{+}, z_{X}^{+}, z_{*}^{+}, P_{1 *}, P_{2 *}, P_{3 X}, P_{4 X}$, and $F_{X}$ are the intermediate variables, and $\kappa$ is the Karman constant. The symbol $*$ indicates $M, T$, or $Q$, and the symbol $X$ indicates $T$ or $Q$.

\section{Appendix F: Mean wind speed in the canopy}

Mean wind speed in the canopy $\left(U_{\mathrm{c}}\right)$ is expressed as

$$
\begin{aligned}
& U_{\mathrm{c}}=\left(U_{\mathrm{h}} / \gamma_{\mathrm{m}} h_{\mathrm{gt}}\right) \times\left\{1-\exp \left(-\gamma_{\mathrm{m}} h_{\mathrm{gt}}\right)\right\}, \\
& U_{\mathrm{h}}=U /\left(1+\ln \left(\left(z_{\mathrm{a}}-h_{\mathrm{gt}}\right)+1\right),\right. \\
& \gamma_{\mathrm{m}}=c_{\mathrm{m}}\left(L / h_{\mathrm{gt}}\right) /\left(2 k^{2}\right),
\end{aligned}
$$

where $U_{\mathrm{h}}$ is the reference wind speed, and $\gamma_{\mathrm{m}}$ is the coefficient of exponential decrease for wind speed in the canopy. 
Acknowledgements. We would like to acknowledge T. Kuawagata and W. Kim at NIAES for useful discussion about land surface modelling. We are also grateful to E. Hatanaka for her help in extensive literature survey. This research was supported by the Environment Research and Technology Development Fund (S-12) and the Program on Development of Regional Climate Change Adaptation Plans in Indonesia (PDRCAPI) of the Ministry of the Environment.

Edited by: H. Sato

Reviewed by: two anonymous referees

\section{References}

Arora, V. K., Bore, G. J., Christian, J. R., Curry, C. L., Denman, K. L., Zahariev, K., Flato, G. M., Scinocca, J. F., Merryfield, W. J., and Lee, W. G.: The effect of terrestrial photosynthesis down regulation on the twentieth-century carbon budget simulated with the CCCma Earth System Model, J. Climate, 22, 6066-6088, 2009.

Baldocchi, D.: An analytical solution for coupled leaf photosynthesis and stomatal conductance models, Tree Physiol., 14, 10691079, 1994.

Ball, J. T.: An analysis of stomatal conductance, PhD Thesis, Stanford University, CA, USA, 1988.

Best, M. J., Pryor, M., Clark, D. B., Rooney, G. G., Essery, R. L. H., Ménard, C. B., Edwards, J. M., Hendry, M. A., Porson, A., Gedney, N., Mercado, L. M., Sitch, S., Blyth, E., Boucher, O., Cox, P. M., Grimmond, C. S. B., and Harding, R. J.: The Joint UK Land Environment Simulator (JULES), model description Part 1: Energy and water fluxes, Geosci. Model Dev., 4, 677-699, doi:10.5194/gmd-4-677-2011, 2011.

Beven, K. J. and Kirkby, M. J.: A physically based, variable contributing area model of basin hydrology, Hydrol. Sci. Bull., 24, 43-69, 1979.

Bondeau, A., Smith, P. C., Zaehle, S., Schaphoff, S., Lucht, W., Cramer, W., Gerten, D., Lotze-Campen, H., Müller, C., Reichstein, M., and Smith, B.: Modelling the role of agriculture for the 20th century global terrestrial carbon balance, Glob. Change Biol., 13, 679-706, 2007.

Boucher, O., Myhre, G., and Myhre, A.: Direct human influence of irrigation on atmospheric water vapour and climate, Clim. Dynam. 22, 597-603, 2004.

Bouman, B. A. M., van Keulen, H., van Laar, H. H., and Rabbinge, R.: The "School of de Wit" crop growth simulation models: A pedigree and historical overview, Agr. Syst., 52, 171-198, 1996.

Bouman, B. A. M., Kropff, M. J., Tuong, T. P., Wopereis, M. C. S., ten Berge, H. F. M., and van Laar, H. H.: Oryza2000: modeling lowland rice, International Rice Research Institute and Wageningen University and Research Centre, Phillippines and Wageningen, the Netherlands, 2001.

Campbell, G. S. and Norman, J. M.: An introduction to environmental biophysics, Springer-Verlag, New York, USA, 1998.

Clapp, R. B. and Hornberger, G. M.: Empirical equations for some soil hydraulic properties, Water Resour. Res., 14, 601-604, 1978.

Collatz, G. J., Ball, J. T., Grivet, C., and Berry, J. A.: Physiological and environmental regulation of stomatal conductance, pho- tosynthesis and transpiration: a model that includes a laminar boundary layer, Agr. Forest Meteorol., 54, 107-136, 1991.

Dai, Y., Dickinson, R. E., and Wang, Y.: A two-Big-Leaf model for canopy temperature, photosynthesis, and stomatal conductance, J. Climate, 17, 2281-2299, 2004.

de Pury, D. G. G. and Farquhar, G. D.: Simple scaling of photosynthesis from leaves to canopies without the errors of big-leaf models, Plant Cell Environ., 20, 537-557, 1997.

FAO: FAOSTAT, Rome, available at: http://faostat.fao.org/ (last access: 5 September 2016), 2015.

Goudriaan, J.: Crop micrometeorology: a simulation study, Centre for Agricultural Publishing and Docummentation, Wageningen, the Netherlands, 1977.

Goudriaan, J. and van Laar, H. H.: Modelling potential crop growth processes: Textbook with exercises, Kluwer Academic Publishers, Dordrecht, the Netherlands, 1994.

Gervois, S., de Noblet-Ducoudré, N., Viovy, N., Ciais, P., Brisson, N., Seguin, B., and Perrier, A.: Including croplands in a global biosphere model: methodology and evaluation at specific sites, Earth Interact., 8, 1-25, 2004.

Hanasaki, N., Kanae, S., Oki, T., Masuda, K., Motoya, K., Shirakawa, N., Shen, Y., and Tanaka, K.: An integrated model for the assessment of global water resources - Part 1: Model description and input meteorological forcing, Hydrol. Earth Syst. Sci., 12, 1007-1025, doi:10.5194/hess-12-1007-2008, 2008.

Hirabayashi, Y., Mahendran, R., Koirala, S., Konoshima, L., Yamazaki, D., Watanabe, S., Kim, H., and Kanae, S.: Global flood risk under climate change, Nature Clim. Change, 3, 816-821, 2013.

Kimura, R. and Kondo, J.: Heat balance model over a vegetated area and its application to a paddy filed, J. Meteorol. Soc. Jpn., 76, 937-953, 1998.

Kucharik, C. J.: Evaluation of a process-based agro-ecosystem model (Agro-IBIS) across the U.S. corn belt: simulations of the interannual variability in maize yield, Earth Interact., 7, 1-33, 2003.

Kueppers, L. M., Snyder, M. A., Sloan, L. C., Cayan, D., Jin, J., Kanamaru, H., Kanamitsu, M., Miller, N. L., Tyree, M., Du, H., and Weare, B.: Seasonal temperature responses to land-use change in the western United States, Global Planet. Change, 60, 250-264, 2008.

Lei, H., Yang, D., Lokupitiya, E., and Shen, Y.: Coupling land surface and crop growth models for predicting evapotranspiration and carbon exchange in wheat-maize rotation croplands, Biogeosciences, 7, 3363-3375, doi:10.5194/bg-7-3363-2010, 2010.

Levis, S, Bonan, G. B., Kluzek, E., Thornton, P. E., Jones, A., Sacks, W. J., and Kucharik, C. J.: Interactive crop management in the Community Earth System Model (CESM1): Seasonal influences on land-atmosphere fluxes, J. Climate, 25, 4839-4859, 2012.

Lobell, D. B., Bala, G., and Duffy, P.B.: Biogeophysical impacts of cropland management changes on climate, Geophys. Res. Lett., 33, L06708, doi:10.1029/2005GL025492, 2006.

Lokupitiya, E., Denning, S., Paustian, K., Baker, I., Schaefer, K., Verma, S., Meyers, T., Bernacchi, C. J., Suyker, A., and Fischer, M.: Incorporation of crop phenology in Simple Biosphere Model (SiBcrop) to improve land-atmosphere carbon exchanges from croplands, Biogeosciences, 6, 969-986, doi:10.5194/bg-6-9692009, 2009. 
Maruyama, A. and Kuwagata, T.: Diurnal and seasonal variation in bulk stomatal conductance of the rice canopy and its dependence on developmental stage, Agr. Forest Meteorol., 148, 1161-1173, 2008.

Maruyama, A. and Kuwagata, T.: Coupling land surface and crop growth models to estimate the effects of changes in the growing season on energy balance and water use of rice paddies, Agr. Forest Meteorol., 150, 919-930, 2010.

Masutomi, Y., Takahashi, K., Harasawa, H., and Matsuoka, Y.: Impact assessment of climate change on rice production in Asia in comprehensive consideration of process/parameter uncertainty in general circulation models, Agr. Ecosyst. Environ., 131, 281291, 2009.

Masutomi,Y., Ono, K., Takimoto, T., Mano, M., Maruyama, A., and Miyata, A.: A land surface model combined with a crop growth model for paddy rice (MATCRO-Rice v. 1) - Part 2: Model validation, Geosci. Model Dev., 9, 4155-4167, doi:10.5194/gmd-94155-2016, 2016.

Oki, T. and Kanae, S.: Global hydrological cycles and world water resources, Science, 313, 1068-1072, 2006.

Oleson, K. W. and Lawrence, D. M.: Technical description of version 4.5 of the Community Land Model (CLM), NCAR Technical Note, NCAR/TN-503+STR, Boulder, CO, USA, 2013.

Osborne, T. M., Lawrence, D. M., Challinor, A. J., Slingo, J. M., and Wheeler, T. R.: Development and assessment of a coupled crop-climate model, Glob. Change Biol., 13, 169-183, 2007.

Osborne, T. M., Slingo, J. M., Lawrence, D. M., and Wheeler, T.: Examining the interaction of growing crops with local climate using a coupled crop-climate model, J. Climate, 22, 1393-1411, 2009.

Osborne, T. M., Gornall, J., Hooker, J., Williams, K., Wiltshire, A., Betts, R., and Wheeler, T.: JULES-crop: a parametrisation of crops in the Joint UK Land Environment Simulator, Geosci. Model Dev., 8, 1139-1155, doi:10.5194/gmd-8-11392015, 2015.

Penning de Vries, F. W. T., Jansen, D. M., ten Berge, H. F. M., and Bakema, A.: Simulation of ecophysiological processes of growth in several annual crops, Centre for Agricultural Publishing and Documentation (Pudoc), Wageningen, the Netherlands, 1989.

Pokhrel, Y. N., Hanasaki, N., Yeh, P. J-F., Yamada, T. J., Kanae, S., and Oki, T.: Model estimates of sea-level change due to anthropogenic impacts on terrestrial water storage, Nat. Geosci., 5, 389-392, 2012.

Rutter, A. J., Morton, A. J., and Robins, P. C.: A predictive model of rainfall interception in forests. II. Generalization of the model and comparison with observations in some coniferous and hardwood stands, J. Appl. Ecol., 12, 367-380, 1975.
Satoh, M., Matsuno, T., Tomita, H., Miura, H., Nasuno, T., and Iga, S.: Nonhydrostatic icosahedral atmospheric model (NICAM) for global cloud resolving simulations, J. Comput. Phys., 227, 34863514, 2008.

Sellers, P. J., Berry, J. A., Collatz, G. J., Field, C. B., and Hall, F. G.: Canopy reflectance, Phtosynthesis, and transpiration. III. A reanalysis using improved leaf models and a new canopy integration scheme, Remote Sens. Environ., 42, 187-216, 1992.

Sellers, P. J., Randall, D. A., Collatz, G. J., Berry, J. A., Field, C. B., Dazlich, D. A., Zhang, C., Collelo, G. D., and Bounoua, L.: A revised land surface parameterization (SiB2) for atmospheric GCMS. Part I: Model formulation, J. Climate, 9, 676705, 1996a.

Sellers, P. J., Los, S. O., Tucker, C. J., Justice, C. O., Dazlich, D. A., Collatz, G. J., and Randall, D. A.: A revised land surface parameterization (SiB2) for atmospheric GCMs. Part II: The generation of global fields of terrestrial biophysical parameters form satellite data, J. Climate, 9, 706-737, 1996b.

Takata, K., Emori, S., and Watanabe, T.: Development of the minimal advanced treatments of surface interaction and runoff, Global Planet. Change, 38, 209-222, 2003.

Tsvetsinskaya, E. A., Mearns, L. O., and Easterling, W. E.: Investigating the effects of seasonal plant growth and development in three-dimensional atmospheric simulations. Part II: Atmospheric response to crop growth and development, J. Climate, 14, 711729, 2001.

Watanabe, M., Suzuki, T., O'ishi, R. Komuro, Y., Watanabe, S., Emori, S., Takemura, T., Chikira, M., Ogura, T., Sekiguchi, M., Takata, K., Yamazaki, D., Yokohata, T., Nozawa, T., Hasumi, H., Tatebe, H., and Kimoto, M.: Improved climate simulation by MIROC5: Mean states, variability, and climate sensitivity, J. Climate, 23, 6312-6335, 2010.

Watanabe, S., Hajima, T., Sudo, K., Nagashima, T., Takemura, T., Okajima, H., Nozawa, T., Kawase, H., Abe, M., Yokohata, T., Ise, T., Sato, H., Kato, E., Takata, K., Emori, S., and Kawamiya, M.: MIROC-ESM 2010: model description and basic results of CMIP5-20c3m experiments, Geosci. Model Dev., 4, 845-872, doi:10.5194/gmd-4-845-2011, 2011.

Watanabe, T.: Bulk parameterization for a vegetated surface and its application to a simulation of nocturnal drainage flow, BoundLay. Meteorol., 70, 13-35, 1994.

Watanabe, T. and Ohtani, Y.: A simple model of shortwaveradiation transport within canopy, J. Agric. Meteorol., 51, 57-60, 1995 (in Japanese). 